\title{
Transcriptome analysis reveals response regulator SO2426-mediated gene expression in Shewanella oneidensis MR-I under chromate challenge
}

\author{
Karuna Chourey ${ }^{\dagger 4,1}$, Wei Wei ${ }^{\dagger 2}$, Xiu-Feng Wan ${ }^{5,3}$ and \\ Dorothea K Thompson*2
}

Address: ${ }^{1}$ Environmental Sciences Division, Oak Ridge National Laboratory, Bethel Valley Road, Oak Ridge, TN 37831 , USA, ${ }^{2}$ Department of Biological Sciences, Purdue University, 915 W. State Street, West Lafayette, IN 47907, USA, 35ystems Biology Laboratory, Department of Microbiology, Miami University, 32 Pearson Hall, Oxford, OH 45056, USA, ${ }^{4}$ Chemical Sciences Division, Oak Ridge National Laboratory, Oak Ridge, TN 37831, USA and 5Influenza Division, Centers for Disease Control and Prevention, 1600 Clifton Road, Atlanta, GA 30333, USA

Email: Karuna Chourey - choureyk@ornl.gov; Wei Wei - weiw@purdue.edu; Xiu-Feng Wan - xwan@cdc.gov;

Dorothea K Thompson* - dthomps@purdue.edu

* Corresponding author †Equal contributors

Published: 21 August 2008

BMC Genomics 2008, 9:395 doi:10.1186/1471-2164-9-395
Received: 5 May 2008

Accepted: 21 August 2008

This article is available from: http://www.biomedcentral.com//47I-2/64/9/395

(c) 2008 Chourey et al; licensee BioMed Central Ltd.

This is an Open Access article distributed under the terms of the Creative Commons Attribution License (http://creativecommons.org/licenses/by/2.0), which permits unrestricted use, distribution, and reproduction in any medium, provided the original work is properly cited.

\begin{abstract}
Background: Shewanella oneidensis MR-I exhibits diverse metal ion-reducing capabilities and thus is of potential utility as a bioremediation agent. Knowledge of the molecular components and regulatory mechanisms dictating cellular responses to heavy metal stress, however, remains incomplete. In a previous work, the $S$. oneidensis so2426 gene, annotated as a DNA-binding response regulator, was demonstrated to be specifically responsive at both the transcript and protein levels to acute chromate $[\mathrm{Cr}(\mathrm{VI})]$ challenge. To delineate the cellular function of SO2426 and its contribution to metal stress response, we integrated genetic and physiological approaches with a genome-wide screen for target gene candidates comprising the SO2426 regulon.

Results: Inactivation of so2426 by an in-frame deletion resulted in enhanced chromate sensitivity and a reduced capacity to remove extracellular $\mathrm{Cr}(\mathrm{VI})$ relative to the parental strain. Time-resolved microarray analysis was used to compare transcriptomic profiles of wild-type and SO2426-deficient mutant S. oneidensis under conditions of chromate exposure. In total, $84 \mathrm{I}$ genes ( $18 \%$ of the arrayed genome) were up- or downregulated at least twofold in the $\Delta$ so2426 mutant for at least one of six time-point conditions. Hierarchical cluster analysis of temporal transcriptional profiles identified a distinct cluster $(n=46)$ comprised of co-ordinately regulated genes exhibiting significant downregulated expression $(p<0.05)$ over time. Thirteen of these genes encoded proteins associated with transport and binding functions, particularly those involved in Fe transport and homeostasis (e.g., siderophore biosynthetic enzymes, TonB-dependent receptors, and the iron-storage protein ferritin). A conserved hypothetical operon (so//88-so//89-so//90), previously identified as a potential target of Furmediated repression, as well as a putative bicyclomycin resistance gene (so2280) and cation efflux family protein gene (so2045) also were repressed in the so2426 deletion mutant. Furthermore, the temporal expression profiles of four regulatory genes including a cpxR homolog were perturbed in the chromate-challenged mutant.
\end{abstract}

Conclusion: Our findings suggest a previously unrecognized functional role for the response regulator SO2426 in the activation of genes required for siderophore-mediated Fe acquisition, Fe storage, and other cation transport mechanisms. SO2426 regulatory function is involved at a fundamental molecular level in the linkage between Fe homeostasis and the cellular response to chromate-induced stress in S. oneidensis. 


\section{Background}

Shewanella oneidensis MR-1, a facultatively anaerobic member of the $\gamma$-class of Proteobacteria, can respire anaerobically by reducing a wide variety of alternative electron acceptors including fumarate, nitrate, elemental sulfur, and such oxidized metals as Fe(III), Mn(IV), and U(VI) [15]. In addition, MR-1 is capable of reducing hexavalent chromium, or chromate $[\mathrm{Cr}(\mathrm{VI})]$, to less toxic and sparingly soluble trivalent chromium [Cr(III)] under both aerobic and anaerobic conditions [6-8]; however, there have been no reports to date of the ability of MR-1 to generate energy for growth using $\mathrm{Cr}(\mathrm{VI})$ as the sole terminal electron acceptor for anaerobic respiration [9]. This plasticity in the use of alternative electron acceptors for anaerobic respiration has engendered interest in S. oneidensis MR-1 as a model environmental organism with potential utility in the bioremediation of dissolved metal ions, and as a consequence, the complete MR-1 genome was sequenced to advance understanding of Shewanella biology [10].

To expand knowledge of metal stress responses in particular, we previously initiated genome-based studies focused on identifying the molecular components involved in the $S$. oneidensis response to chromate [11-13], an anthropogenic pollutant widely distributed in the environment due to its prevalent use in manufacturing and military industries $[14,15]$. Chromate toxicity is associated with the generation of reactive oxygen species during the intracellular partial reduction of $\mathrm{Cr}(\mathrm{VI})$ to the highly reactive radical $\mathrm{Cr}(\mathrm{V})$ by various in vivo nonspecific reductants or cellular one-electron reductases [16]. Our previous work employing DNA microarrays and multidimensional liquid chromatography-tandem mass spectrometry (LC-MS/MS) demonstrated that a functionally unknown DNA-binding response regulator (designated SO2426) in MR-1 was reproducibly and significantly upregulated at both the transcript and protein levels in response to acute chromate challenge $[11,13]$.

In accordance with its ability to adapt to various environmental conditions, the $S$. oneidensis MR-1 genome encodes a relatively large repertoire of transcriptional regulators, including 88 predicted two-component regulatory system proteins consisting of 23 histidine protein kinase (HK) genes, 57 response regulators (RR), and 8 HK-RR hybrids [10]. Prototypical two-component systems, which constitute the predominant mechanism used by bacteria for coupling environmental signals to specific adaptive responses, comprise a sensor histidine kinase and a cognate response regulator [17-19]. Fundamental to signal transduction is a phosphotransfer mechanism that forms the core of both mechanistically simple as well as more complex signaling pathways. In this scheme, a membrane-bound sensor kinase catalyzes ATP-dependent autophosphorylation at a conserved histidine residue in the HK cytoplasmic autokinase domain in response to a specific environmental cue. The signal is transduced through transfer of the phosphoryl group from the phosphoHis of the HK to a conserved aspartate residue within the receiver module of a cytosolic RR. Phosphorylation of the RR alters its affinity for DNA, leading to the transcriptional activation or repression of specific genes. An essential feature of two-component systems is that specific histidine kinases and response regulators function as cognate pairs and are often arranged within the same operon. The S. oneidensis SO2426 protein appears to be an orphan $\mathrm{RR}$ as defined by the fact that there is no obvious cognate histidine kinase flanking the so2426 gene or proximally located based on the genome annotation [10].

The primary aim of the present study was to investigate the function of the uncharacterized SO2426 regulator within the context of chromate stress by performing a genome-wide screen for potential target genes of this RR in S. oneidensis MR-1. Toward this end, we created an so2426 in-frame deletion mutant and compared its global transcriptional profiles with that of wild-type MR-1 in response to chromate challenge using time-resolved microarray experiments. Comparative transcriptome analysis suggested that SO2426 was associated with the activation of genes involved in siderophore-mediated $\mathrm{Fe}$ uptake, Fe storage, and possibly other cation transport processes.

\section{Results and discussion}

\section{Sequence analysis of the response regulator SO2426}

Based on its nucleotide sequence, the so2426 gene of $S$. oneidensis MR-1 is predicted to encode a 237 -amino-acid protein with a calculated molecular mass of $27.4 \mathrm{kDa}$ [10]. Comparative sequence analysis using ClustalW [20] revealed that SO2426 shares sequence similarity to CpxR from Vibrio cholerae (36\% identity) and E. coli (34\%), and to OmpR from V. cholerae (29\%) and E. coli (27\%) (Figure $1)$. In addition, SO2426 orthologs are present and conserved among many of the Shewanella species sequenced to date, including Shewanella sp. MR-7 (88\% sequence identity), Shewanella sp. MR-4 and sp. ANA-3 (87\%), S. baltica OS195 (74\%), S. putrefaciens 200 and CN-32 (73\%), S. woodyi ATCC 51908 (60\%), S. amazonensis SB2B (61\%), and S. frigidimarina NCIMB 400 (49\%).

The deduced SO2426 protein consists of an N-terminal CheY-like receiver domain and a C-terminal winged-helix DNA-binding domain. The N-terminal portion of SO2426 (amino acids 13-124; see Figure 1) shares homology with receiver domains and contains the highly conserved signature residues that are thought to constitute the phosphorylated acid-pocket active site [19,21]. In CheY, these residues correspond to Asp12, Asp13, and Asp57, with Thr87 and Lys109 completing the cluster of 


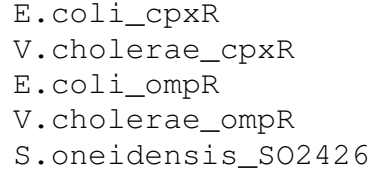

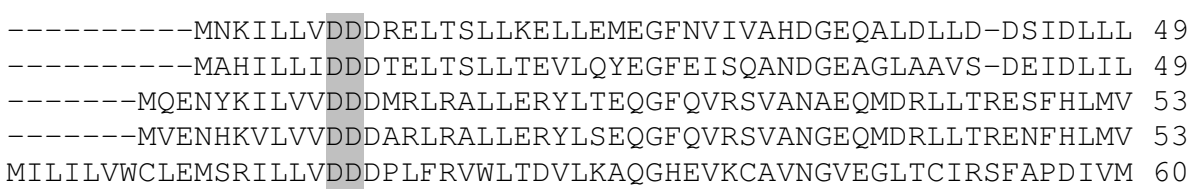
MILILVWCLEMSRILLVDDDP LFRVWLTDVLKAQGHEVKCAVNGVEGLTCIRSFAPDIVM 60

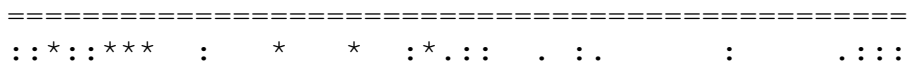

LDVMMPKKNGIDTLKALR-QTHQTPVIMLTARGSELDRVLGLELGADDYLPKPFNDRELV 108 LDVMMP KLNGMETLKRLR-EKWATPVLMLTAKGEE IDRVIGLELGADDYLPKPF SDRELL 108 LDLMLP GEDGLS ICRRLRSQSNPMP I IMVTAKGEEVDRIVGLEIGADDY IPKPFNPRELL 113 LDLMLP GEDGLS ICRRLRNSNNMIP I LMLTAKGDE IDR IVGLEVGADDYLPKPFNPRELL 113 LDLVMP QMD GF ELLQARE---CMTP IMMLSARDNEEDRIRSYELGADDF LTKPF S IKELL 117

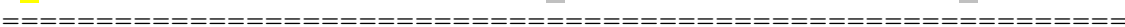

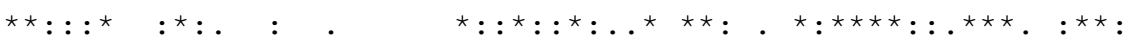

ARIRAILRRSHWSEQQQNNDNGSPTLEVDALVLNP GRQEASFDGQTLELTGTEFTLLYLL 168 ARIRA I LRRTQNGLTP KNSD----VIECQD IQVYP GKQEAYCQGQLLELTTTEFALLTHF 164 ARIRAVLRRQANELPGAP SQE-EAVIAFGKFKLNLGTREMFREDEPMP LTSGEFAVLKAL 172 ARIKAVLRRQVVEAP GAP SAE-ETI IEFGEFRLNLGTREMFRGEEAMP LTSGEFAVLKAL 172 VRLQAIERRLVQ--RPKPPMAVEQVATIQSVRFDETAYKITIGKHAVELTQTEFRLFKYL 175

$=====$
$*:: \star: \star \star$

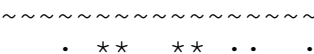

AQHLGQVVSREHLSQEVLGKRLTPFDRAIDMHISNLRRKLPDRKDGHPWFKTLRGRGYLM 228 VQSP GATLTKEMLS IEVLGKHLAAFDRA IDMHVSNLRKKLPERPDGKARIKTLRGRGYLM 224 VSHPREP LSRDKLMNLARGREYSAMERS IDVQISRLRRMVEEDPAHPRYIQTVWGLGYVF 232 VTNAREP LSRDKLMNMARGREYSAMERS IDVQISRLRRMLEVDP SKPRYIQTVWGLGYVF 232 FERKGQVITKQELQKSVLQKDLGRFDRNLDMHISNTRRKLANTRLPRTLINTVRGQGYSF 235

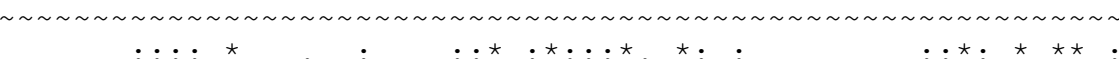

VSAS---- 232

VQEE---- 228

VPDGSKA- 239

VPDGKAAN 240

SA------ 237

\section{Figure I}

Sequence alignment of S. oneidensis SO2426 with other two-component response regulators. ClustalW [20] was used to perform a multiple sequence alignment consisting of S. oneidensis SO2426 (GenBank ID 243484I9), CpxR from E. coli (GenBank ID 16I3I752) and Vibrio cholerae (GenBank ID 147675245), and OmpR from E. coli (GenBank ID I6I3I282) and V. cholerae (GenBank ID |4767357I). The region underlined with " $="$ is the aligned regulator receiver domain with predicted domain (SO2426: positions 13-124), and the region denoted with " $"$ " is the aligned C-terminal domain containing the wHTH DNA-binding motif (SO2426: positions I58-235). Boldface letters highlighted in grey indicate conserved signature residues of receiver domains [19]. Residue D62 is predicted as 4-aspartylphosphate, the putative phosphorylation site (highlighted in yellow). The star, colon, and dot notations rank the sequence conservation from high to low.

conserved residues surrounding the phosphorylation site [19]. Thr87 and Lys109, although not absolutely required for phosphorylation, have been implicated in contributing to the phosphorylation-induced conformational change [22-24]. S. oneidensis SO2426 contains three contiguous aspartate residues near its $\mathrm{N}$-terminus at positions 18,19 and 20, and there is a conserved substitution to serine at the equivalent position of 87 . The phosphateaccepting aspartic residue Asp57 and Lys109 (relative to
CheY residue numbering) are retained at equivalent positions in the SO2426 primary sequence. It is presently not known whether a cognate histidine kinase interacts with SO2426 or whether phosphorylation plays a regulatory role in the cellular activity of SO2426. The fact that SO2426 contains the highly conserved residues constituting the active phosphorylation pocket (D18, D19, D62, and K109) suggests that the protein might be differentially controlled by phosphorylation. Furthermore, it 
remains to be determined whether the regulatory activity of SO2426 is modulated in response to environmental or intracellular stimuli.

The C-terminal portion of SO2426 (amino acids 158235; see Figure 1) contains a predicted winged helix-turnhelix (wHTH) motif indicative of the DNA-binding domains of response regulators in the $\mathrm{OmpR} / \mathrm{PhoB}$ subfamily [25-27]. The basic structure of the carboxy-terminal domains of $\mathrm{OmpR} / \mathrm{PhoB}$ subfamily response regulators is characterized by an amino-terminal four-stranded $\beta$ sheet, a central three-helical bundle, and a C-terminal $\beta$-strand hairpin (the wing), which provides an additional interface for DNA contact [26].

\section{The so2426 gene is co-transcribed in an operon}

Based on the MR-1 genome annotation, SO2426 is an apparent orphan response regulator given that the so2426 locus is not linked with a gene that encodes a potential cognate histidine kinase. As schematically represented in Figure $2 \mathrm{~A}$, so2426 is tightly clustered with four functionally unknown downstream genes, all possessing the same transcriptional polarity. Located immediately downstream of so2426 with a short intergenic spacer of $10 \mathrm{bp}$ is a small ORF (132 bp) predicted to encode a soluble hypothetical protein (SO2425), which was shown previously to be induced at the transcriptional level in response to acute chromate challenge [11]. The gene cluster is also characterized by ORFs encoding a zinc carboxypeptidase domain protein (SO2424), a hypothetical protein (SO2423), and a conserved hypothetical protein (SO2422) (Figure 2A). The so2423 ORF overlaps so2422 by 3 bp based on the MR-1 genome annotation (http:// www.tigr.org). The so2426 region also includes a gene encoding a putative TonB-dependent receptor (SO2427) positioned approximately $170 \mathrm{bp}$ upstream of so2426. Putative $\rho$-independent transcription terminators were identified downstream of the so2427 and so2422 ORFs (http://cmr.tigr.org; [28]).

Reverse transcription-PCR (RT-PCR) experiments were performed to determine whether the so2427-so2422 gene cluster is transcribed as a polycistronic mRNA. Primers P1-P9 (Figure 2A) used in the PCR reactions following reverse transcription with random hexamers were designed to amplify regions spanning two or more ORFs in order to establish the transcriptional organization. To assess the reproducibility of the results, multiple independent RT-PCR experiments were carried out using different preparations of total RNA isolated from untreated or chromate-treated MR-1 cells. Figure 2B shows a representative gel of the RT-PCR results using the entire suite of primers. Each PCR product was confirmed by DNA sequencing. No products were amplified when using either total RNA as the template for PCR amplification
(Figure 2B) or primers complementary to an intergenic region located outside of the so2427-so2422 cluster (results not shown), thus indicating the absence of contaminating genomic DNA in the total RNA preparations. S. oneidensis MR-1 genomic DNA was used as a positive control for the PCR conditions (results not shown). Amplicons of the expected sizes, i.e., $0.85 \mathrm{~kb}$ for primers $\mathrm{P} 1 / \mathrm{P} 5,1.9 \mathrm{~kb}$ for primers P1/P6, $2.3 \mathrm{~kb}$ for primers P1/P7, $2.5 \mathrm{~kb}$ for primers $\mathrm{P} 2 / \mathrm{P} 8$, and $3.3 \mathrm{~kb}$ for primers $\mathrm{P} 9 / \mathrm{P} 3$, were obtained (Figure 2B), indicating that the so2427so2422 region is co-transcribed as a polycistronic mRNA under no-metal and chromate-amended conditions. However, given the presence of a putative $\rho$-independent terminator immediately downstream of so2427, we cannot rule out the possibility that the product generated from the so2427-so2426 transcript might be due to readthrough transcription.

\section{Characterization of the so2426 promoter region}

The transcription start site of the so2426 gene was localized using 5' RACE analysis of mRNA transcripts isolated from wild-type cells grown in either the absence or presence of chromate. Two clear 5' termini, both mapping to A residues and corresponding to positions 25 and $27 \mathrm{bp}$ upstream of a second in-frame ATG (amino acid residue M11) (Figure 3), were obtained by DNA sequencing of the 5' RACE amplicons. These sites are located at positions 4 and 6 bp downstream of the initial ATG (M1) start codon, indicating that the original sequence annotation for this gene is incorrect and that the second ATG (M11) most likely constitutes the translation start codon for SO2426. The so2426 transcription start point indicated potential 10 and -35 basal promoter elements, 5'-TAatAT and 5'gTGACA, respectively, with a 15-bp spacing between them. The putative -10 promoter sequence (5'-TAatAT) has a $4 / 6$ match to the consensus $\sigma^{70}$-dependent -10 hexamer element (5'-TATAAT) from E. coli. Interestingly, located one base upstream of the -10 hexamer is the extended -10 element 5'-TaTG-3' (Figure 3), identified by Mitchell et al. [29] and shown to be an important determinant for promoter activity. Finally, the identified so2426 promoter region contains the putative -35 element 5'gTGACA, which is a strong match $(5 / 6)$ to the E. coli consensus -35 hexamer (5'-TTGACA).

Further analysis of the so2426 upstream regulatory region revealed the presence of a putative recognition site for the ferric uptake regulator (Fur), the iron-binding global transcriptional regulator that serves as the dominant sensor of Fe availability in both gram-positive and gram-negative bacteria (for a review, see [30]). A putative palindromic Fur box, 5'-AAATGAtATTgATTcTCgTTT-3', which closely matched our previously derived predicted Fur-binding motif for S. oneidensis MR-1 [31], was identified at positions -5 to +16 immediately downstream of the -10 pro- 

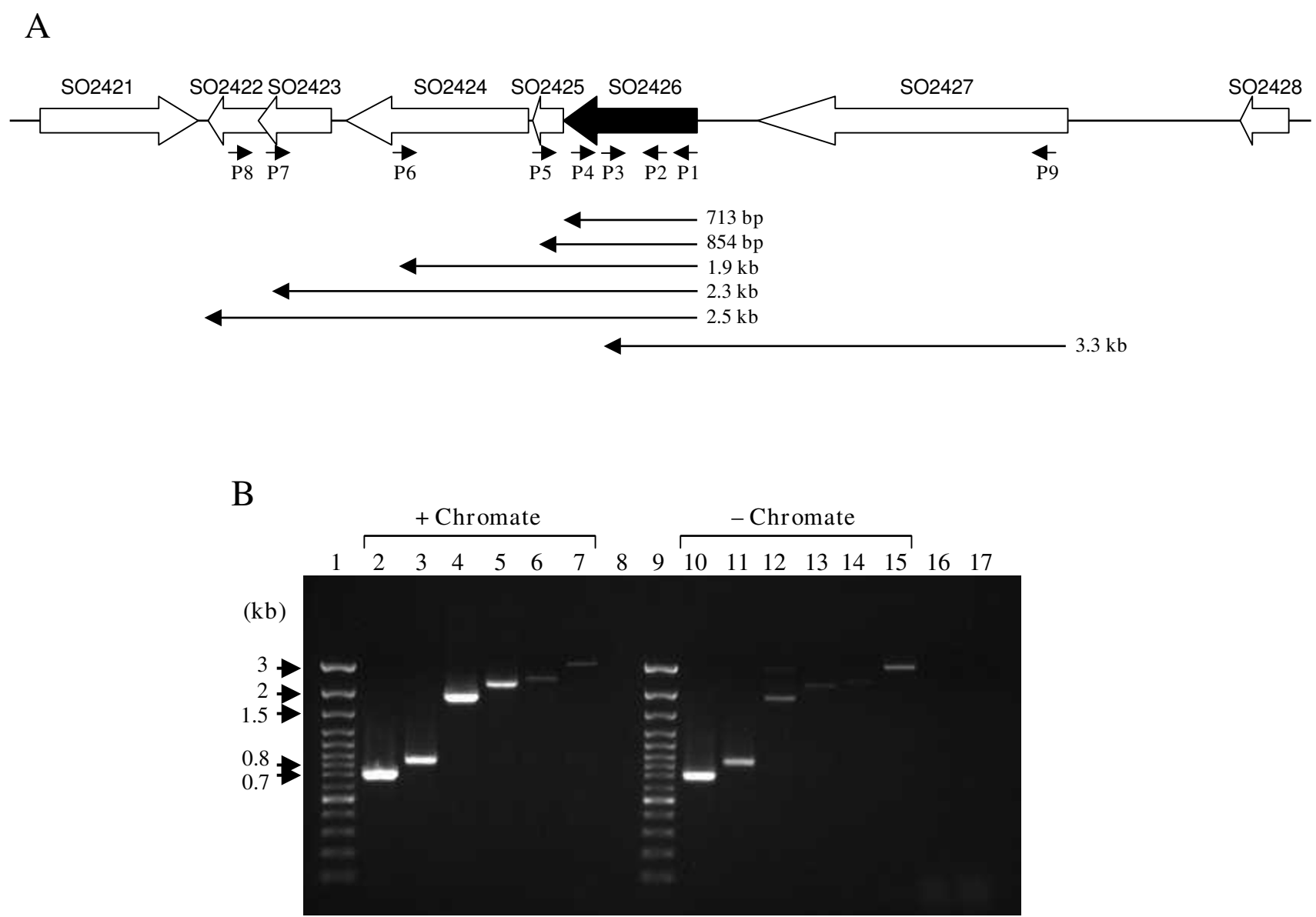

\section{Figure 2}

Structural organization of the S. oneidensis MR-I so2426 locus. (A) Schematic representation of the so2426 gene region. ORFs located upstream and downstream of so2426 (black arrow) are indicated by open arrows, which also indicate the direction of transcription. The deduced proteins of the ORFs flanking so2426 have the following annotations based on the J. Craig Venter Institute's Comprehensive Microbial Resource http://cmr.tigr.org: SO242I is a L-asparaginase I; SO2422 is a conserved hypothetical protein; SO2423 is a hypothetical protein; SO2424 is a zinc carboxypeptidase domain protein; SO2425 is a hypothetical protein; SO2426 is a DNA-binding response regulator; SO2427 is a putative TonB-dependent receptor; and SO2428 is a hypothetical protein. The locations of the oligonucleotide primers (PI-P9) used for RT-PCR are shown by the small solid arrows. The expected PCR product sizes for the different primer pairs are given below. (B) Agarose gel (I\%) electrophoresis of amplified DNA fragments derived from $S$. oneidensis MR-I cDNA templates under conditions of chromate stress or no stress. Lane designations: (I) I00-bp DNA ladder; (2) PCR primer pair PI/P4, (3) PI/P5, (4) PI/P6, (5) PI/P7, (6) P2/P8, (7) P9/P3, (8) blank, (9) I00-bp DNA ladder, (I0) PI/P4, (I I) PI/P5, (I2) PI/P6, (I3) PI/P7, (I4) P2/P8, (I5) P9/P3, (I6) chromate-treated total RNA used as the template in PCR amplification with PI/P4 (negative control), and (I7) non-stressed total RNA used as the template in PCR amplification with PI/P4 (negative control).

moter element and overlapped the mapped transcription start sites for so2426 (Figure 3). Identification of a Fur box is consistent with our previous microarray studies demonstrating increased so2426 mRNA levels in a S. oneidensis MR-1 fur knockout strain [31] and suggests that expression of the SO2426 response regulator might be subject to Fur-mediated repression.

\section{Growth and chromate reduction kinetics of the so2426 deletion mutant}

A cre-lox recombination method $[32,33]$ was used to create a nonpolar in-frame deletion of the so2426 locus in MR-1 for the purpose of analyzing in depth the functional role of this response regulator in metal stress responses (see Methods for a detailed description). The deleted segment was $721 \mathrm{bp}$ in length and corresponded to positions 
ÄTTCTC்GTiTGGTGCTTAGAAATGAGTAGAATACTGTTAGTCGATGATGATCCTTTATTC

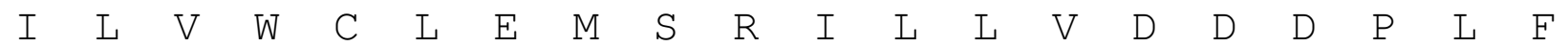
CGAGTGTGGTTAACTGATGTGCTCAAAGCACAAGGACATGAGGTTAAATGTGCAGTAAAT $\begin{array}{lllllllllllllllllllll}R & V & W & \mathrm{~L} & \mathrm{~T} & \mathrm{D} & \mathrm{V} & \mathrm{L} & \mathrm{K} & \mathrm{A} & \mathrm{Q} & \mathrm{G} & \mathrm{H} & \mathrm{E} & \mathrm{V} & \mathrm{K} & \mathrm{C} & \mathrm{A} & \mathrm{V} & \mathrm{N}\end{array}$ GGTGTTGAAGGGCTTACATGCATCCGCTCTTTTGCGCCCGATATCGTTATGCTCGATCTG $\begin{array}{llllllllllllllllllllllllllll}G & V & E & G & L & T & C & I & R & S & F & A & P & D & I & V & M & L & D & L\end{array}$ GTAATGCCGCAAATGGATGGTTTTGAGCTATTGCAGGCAAGGGAGTGTATGACGCCGATA $\begin{array}{llllllllllllllllllll}V & M & P & Q & M & D & G & F & E & L & L & Q & A & R & E & C & M & T & P & I\end{array}$ ATGATGTTATCAGCCCGCGATAATGAAGAAGACAGGATACGAAGCTATGAACTTGGTGCA $\begin{array}{llllllllllllllllllll}M & M & L & S & A & R & D & N & E & E & D & R & I & R & S & Y & E & L & G & A\end{array}$ —2426-GSP2 GATGATTTTTTGACTAAGCCTTTTAGCATTAAGGAGCTATTGGTACGTTTGCAGGCCATA $\begin{array}{llllllllllllllllllll}D & D & F & L & T & K & P & F & S & I & K & E & L & L & V & R & L & Q & A & I\end{array}$ $\longleftarrow 2426-G S P 1$ GAGCGACGGTTAGTGCAGCGGCCCAAGCCGCCAATGGCCGTTGAGCAAGTCGCAACAATT \begin{tabular}{llllllllllllllllllll}
\hline & $\mathrm{R}$ & $\mathrm{R}$ & $\mathrm{L}$ & $\mathrm{V}$ & $\mathrm{Q}$ & $\mathrm{R}$ & $\mathrm{P}$ & $\mathrm{K}$ & $\mathrm{P}$ & $\mathrm{P}$ & $\mathrm{M}$ & $\mathrm{A}$ & $\mathrm{V}$ & $\mathrm{E}$ & $\mathrm{Q}$ & $\mathrm{V}$ & $\mathrm{A}$ & $\mathrm{T}$ & $\mathrm{I}$
\end{tabular} CAATCGGTTAGATTTGACGAAACTGCCTACAAGATTACTATCGGCAAACAT...

\begin{tabular}{lllllllllll}
\hline & $S$ & $V$ & $R$ & $F$ & $D$ & $E$ & $T$ & $A$ & $Y$ & $K$
\end{tabular}

\section{Figure 3}

Nucleotide sequence of the so2426 promoter region and $\mathbf{N}$-terminal coding region. The transcriptional start site $(+1)$ is indicated by arrows, and putative -10 and -35 basal promoter elements are presented in boldface and underlined. Closed circles indicate conserved residues matching a predicted Fur-binding recognition site. The annotated (original) translation start codon ( $\mathrm{MI}$ residue) of so2426 is shown in boldface. 5'-RACE results described here indicate that the annotated translation start codon is incorrect, and residue MI I constitutes the actual start codon. The 5'-RACE primers used to identify the transcription start site are shown in italics and underlined.

-77 to +645 (S. oneidensis MR-1 genome coordinates 2534690 and 2533969) from the annotated translational start site, leaving only 69 nucleotides of the so2426 gene intact at the C-terminal end. The growth behavior of the $\Delta$ so2426 mutant in response to $\mathrm{Cr}(\mathrm{VI})$ was examined using a Bioscreen $\mathrm{C}$ reader to monitor culture turbidity $\left(\mathrm{OD}_{600}\right)$ at 30-min intervals under aerobic conditions over $72 \mathrm{~h}$. As shown in Figure 4A, growth of the S. oneidensis $\Delta s o 2426$ strain was comparable to the wild type in LB broth without added chromate. By contrast, growth of the $\Delta s o 2426$ mutant was inhibited to a greater extent than the wild type in the presence of $0.3 \mathrm{mM}$ chromate as evident from the longer time interval required before the commencement of exponential growth.

To determine whether deletion of so2426 affected the ability of MR-1 to remove extracellular $\mathrm{Cr}(\mathrm{VI})$ from the medium, the wild-type and mutant strains were challenged with $0.3 \mathrm{mM}$ chromate (the same final concentration used for the transcriptomic studies) when cells reached mid-log phase $\left(\mathrm{OD}_{600}, 0.5\right)$. Residual hexavalent chromium was measured spectrophotometrically at $3-\mathrm{h}$ 
A

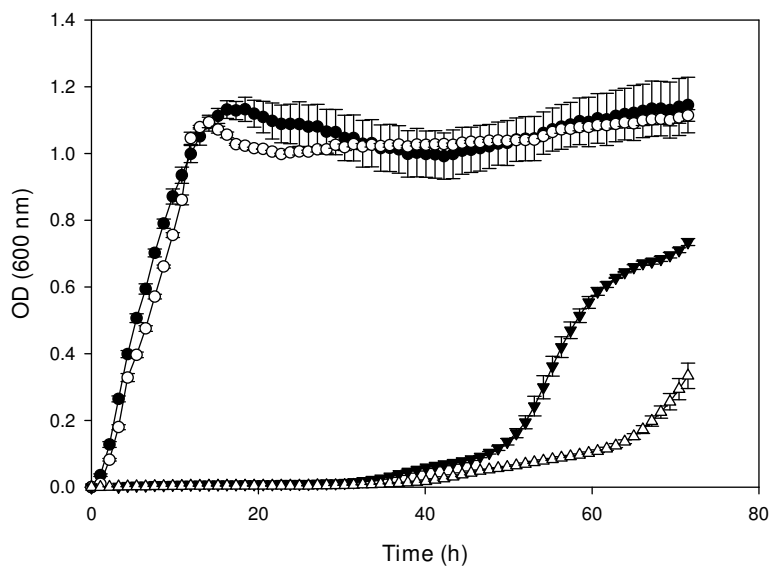

B

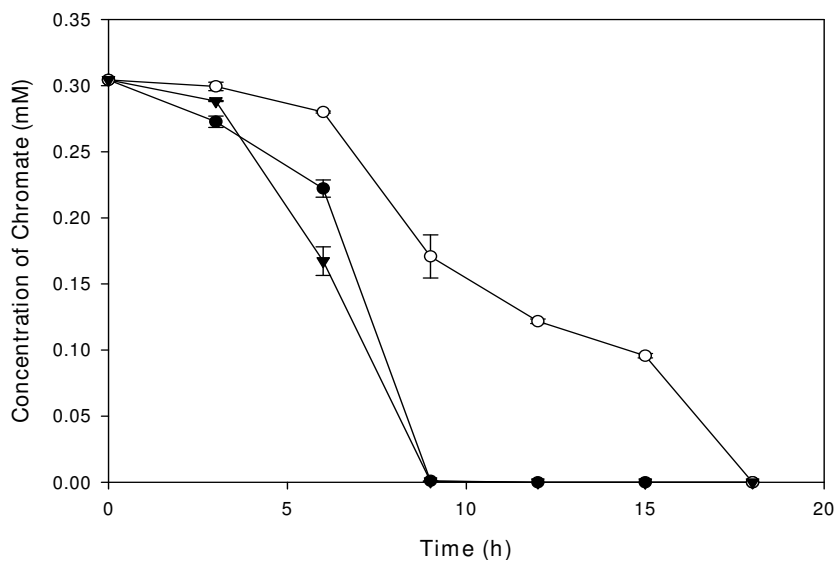

\section{Figure 4}

Growth and chromate reduction kinetics of S. oneidensis MR-I wild type and the $\Delta$ so2426 mutant. (A) Wild-type $(O)$ and mutant $(O)$ cultures were cultivated in LB broth without the addition of chromate under aerobic conditions and compared to wild-type $(\nabla)$ and mutant $(\triangle)$ cultures grown in LB broth amended with a final $\mathrm{K}_{2} \mathrm{CrO}_{4}$ concentration of 0.3 mM. (B) $\mathrm{Cr}(\mathrm{VI})$ removal rates for the S. oneidensis MR-I (O), $\Delta$ so2426 (O), and complemented $\Delta$ so2426(so2426 $\left.6^{+}\right)(\nabla)$ strains in LB broth supplemented with $0.3 \mathrm{mM}$ chromate. The different cultures were challenged with $0.3 \mathrm{mM} \mathrm{K}_{2} \mathrm{CrO}_{4}$ when cells reached an $\mathrm{OD}_{600}$ of 0.5 (mid-log point). The error bars indicate standard deviations of triplicate measurements.

intervals using the chromogenic 1,5-diphenylcarbazide (DPC) method [34]. The chromate disappearance profiles in Figure 4B show that the parental MR-1 strain removed $100 \%$ of the external $\mathrm{Cr}(\mathrm{VI})$ within $9 \mathrm{~h}$, while the $\Delta s o 2426$ mutant transformed approximately $50 \%$ within the same time period. No abiotic conversion of chromate was observed for the cell-free LB control (data not shown).

Complementation experiments were performed to ascertain whether the enhanced chromate sensitivity and slower chromate transformation rate for the so2426 null mutant were due to the deletion of the response regulator gene so2426 and not to secondary-site mutations introduced during the mutagenesis procedure. A complemented $\Delta s o 2426$ strain was constructed by cloning the full-length so2426 wild-type ORF plus 100 bp of contiguous upstream sequence into the broad-host-range vector pBBR2426 as described in the Methods. Transformation of pBBR2426 into the $\Delta s o 2426$ mutant resulted in a complemented strain, designated $\Delta s o 2426\left(s o 2426^{+}\right)$. Genetic complementation of the so2426 gene in the mutant strain restored growth (data not shown) and $\mathrm{Cr}(\mathrm{VI})$ reduction capacity to near wild-type levels (Figure $4 \mathrm{~B}$ ), thus reaffirming the integral role of SO2426 in the cellular response to chromate.

\section{Temporal transcriptome analysis of $\Delta$ so2426 and wild- type strains}

Prior to this study, nothing was known about the regulatory targets of the $\mathrm{OmpR}$ family response regulator
SO2426. To investigate the effect of the so2426 deletion on global gene expression and to identify candidate target genes under SO2426 control, the chromate-perturbed transcriptomes of the $\Delta s o 2426$ mutant and the S. oneidensis MR-1 wild type were compared using whole-genome microarray analysis. Time-series microarray experiments were performed in which global transcriptional profiles of the wild type and the $\Delta s o 2426$ mutant strains were compared at 5, 30, 60, 90, $180 \mathrm{~min}$, and 24 hours following the addition of $\mathrm{K}_{2} \mathrm{CrO}_{4}(0.3 \mathrm{mM}$ final concentration) to mid-exponentially growing cells (see Additional file 1 for a complete list of the processed microarray data). Genes with altered expression ratios of $\geq 2$-fold for at least one of the time points and having a $p$ value of $<0.05$ were considered to be significantly changed and were further analyzed using clustering methods. Overall, microarray expression profiling revealed that 82 (5 min), 90 (30 min), 80 (60 min), 109, (90 min), 443 (180 min), and $465(24 \mathrm{~h})$ genes were induced in the $\Delta$ so2426 mutant under chromate exposure, whereas 125 (5 min), 81 (30 min), 56 (60 min), 105 (90 $\mathrm{min}), 314$ (180 $\mathrm{min})$, and 364 ( $24 \mathrm{~h}$ ) genes were repressed. The total number of differentially expressed genes was substantially less at the shorter, acute exposure times (i.e., 5, 30, 60, and $90 \mathrm{~min}$ ) compared to the longer exposure periods (i.e., $180 \mathrm{~min}$ and $24 \mathrm{~h}$ ), at which point other effects such as accumulation of intracellular chromium (hexavalent and/or reduced forms) and stationary phase growth are likely impacting global expression profiles. 
Quantitative real-time RT-PCR (qRT-PCR) analysis was employed to assess the general quality of the microarray data by providing an independent measurement of gene expression for a small subset of genes. The five genes (so0404, so2426, so3670, so1826, and so3585) selected for comparative qRT-PCR displayed downregulated or unaltered expression patterns at the 180-min time point of chromate exposure based on microarray hybridization. Comparison of gene expression levels as determined by microarray and qRT-PCR analyses indicated a high degree of concordance, with a Pearson's correlation coefficient $(r)$ value of 0.99 (data not shown). For the mutant strain, both microarray hybridization and qRT-PCR indicated that so2426 expression levels were not detectable above background, thus providing additional confirmation of deletion of the so2426 gene.

\section{Functional classification of genes differentially expressed in the $\Delta$ so2426 mutant}

Pairwise complete-linkage clustering was used to identify groups of potentially co-ordinately regulated genes among the 841 ORFs ( $18 \%$ of the arrayed genome) showing a twofold or greater statistically significant $(p<0.05)$ change in expression for at least one time point during $\mathrm{Cr}(\mathrm{VI})$ exposure. One particularly noteworthy cluster of similarly expressed genes (Cluster A in Figure 5) comprises 46 genes with functions distributed across the following role categories: cellular processes (2 genes), energy metabolism (9 genes), hypothetical proteins (17 genes), protein synthesis (1 gene), regulatory functions/signal transduction (4 genes), and transport and binding proteins (13 genes). These clustered genes displayed a distinct pattern of downregulated expression in the $\Delta s 02426$ mutant relative to the wild-type MR-1 strain, particularly at the earlier time points $(5,30,60$, and $90 \mathrm{~min})$ of chromate exposure (see Table 1). This is consistent with our previous studies demonstrating that the wild-type so2426 gene was induced at the transcriptional level early in $\mathrm{Cr}(\mathrm{VI})$ exposure, i.e. $90 \mathrm{~min}$ or less, but not at $24 \mathrm{~h}$ posttreatment $[11,12]$. Closer inspection of the 46 potentially co-regulated genes (Table 1) revealed that many of the transport/binding, hypothetical, and regulatory genes were shown previously to be upregulated in wild-type MR-1 cells in response to chromate treatment $[11,13]$, thus suggesting that these ORFs are candidate gene targets of positive control by SO2426. The genes constituting Cluster A are discussed in greater detail in the sections below.

Cluster B (Figure 5) includes 20 genes, three of which encode AcrB/AcrD/AcrF family proteins (SO1882, SO3484, SO4692) presumably involved in drug efflux and resistance. All of these 20 genes showed decreased expression in the $\Delta$ so2426 mutant except at the 24-h time point, where mRNA levels increased (Figure 5 and Addi- tional file 1). Notably, Cluster B also contains genes so0392 (putative lipoprotein) and so4688 (glycosyl transferase, group 2 family protein), both with annotated functions associated with the cell envelope, as well as $c p x A$ (so4478). In E. coli, CpxA is the sensory inner membrane kinase that functions with its cognate partner, a cytoplasmic response regulator (CpxR), in a prototypical twocomponent system to sense and respond to perturbations in the bacterial cell envelope (reviewed in [35]). S. oneidensis cpxR also displayed downregulated temporal expression profiles in the $\Delta s 02426$ mutant under chromate challenge but grouped with genes in Cluster A.

\section{Genes encoding transport and binding functions}

Thirteen of the genes in Cluster A have annotated functions in metal transport and binding, in particular $\mathrm{Fe}$ acquisition and homeostasis: $f t n$ (ferritin), so1580 (TonBdependent heme receptor), so1771 (GntP family permease), so2045 (cation efflux family protein), alcA (siderophore biosynthesis protein), so3031 and so3032 (both putative siderophore biosynthesis proteins encoded immediately downstream of alcA), so3033 (ferric alcaligin siderophore receptor), so3063 (sodium:alanine symporter family protein), so4150 (putative transporter), viuA (ferric vibriobactin receptor), so4712 (putative $\mathrm{ABC}$ transporter, ATP-binding protein), and so4743 (putative TonBdependent receptor). In contrast to the TonB-dependent receptor genes $s 01580$ and so4743, either no significant change or a maximal twofold decrease at the 180-min time point was observed for so2427 (putative TonBdependent receptor), located directly upstream of the so2426 response regulator gene. Of the 13 genes with transport and binding functions in Cluster $\mathrm{A}$, ten ORFs (ftn, so1580, so2045, alcA-so3031-so3032, so3033, so3063, viuA, so4743) were shown in an earlier study to be induced in chromate-challenged wild-type MR-1 cells compared to untreated cells $[11,13]$. Temporal expression patterns for these genes demonstrated that they were downregulated 2 - to 20 -fold in the $\Delta$ so2426 strain over the 180 -min time course (Table 1), suggesting that SO2426 acts as a direct or indirect positive regulator of a subset of $\mathrm{Fe}$ uptake and storage genes in S. oneidensis.

The alcA-so3031-so3032 operon encodes proteins required for siderophore biosynthesis in MR-1 [36], and the product of gene so3033 is predicted to allow for the cellular utilization of the structurally undetermined MR-1 siderophore. The differential profiles for these four genes were characterized by a peak in down-regulated expression (ranging from $\sim 7$ - to 17 -fold) at the 180 -min time interval post chromate addition, followed by no significant change in expression at $24 \mathrm{~h}$ (Table 1). The first gene in the siderophore biosynthetic operon shows $48 \%$ sequence identity to Bordetella pertussis alcA, which is required for alcaligin production [37], while the two 
Table I: Selected genes with down-regulated expression profiles in the $\Delta$ so2426 mutant relative to wild-type MR-I

\begin{tabular}{|c|c|c|c|c|c|c|c|}
\hline \multirow[b]{3}{*}{ Gene } & \multirow[b]{3}{*}{ Description } & \multicolumn{6}{|c|}{ Mean ( $\Delta$ so2426/WT) mRNA ratio $\dagger$} \\
\hline & & \multicolumn{6}{|c|}{ Time (min) post $\mathrm{Cr}(\mathrm{VI})$ addition } \\
\hline & & 5 & 30 & 60 & 90 & 180 & 1440 \\
\hline \multicolumn{8}{|c|}{ Cellular processes } \\
\hline SO2280 & Bicyclomycin resistance protein & 0.64 & 0.36 & 0.43 & 0.23 & 0.24 & 0.39 \\
\hline SO4274 & Undecaprenol kinase, putative & 0.67 & $0.7^{*}$ & 0.57 & $0.56^{*}$ & $0.8^{*}$ & 0.36 \\
\hline \multicolumn{8}{|c|}{ Energy metabolism } \\
\hline SOOIOI & Formate dehydrogenase $(f d n G)$ & 0.3 & 0.32 & 0.55 & 0.56 & 0.29 & 0.36 \\
\hline SO0102 & Formate dehydrogenase $(f d n H)$ & 0.37 & 0.31 & 0.72 & 0.53 & 0.25 & $0.67^{*}$ \\
\hline SO0104 & FdhE protein $(f d h E)$ & 0.32 & $0.74^{*}$ & 0.45 & $0.61^{*}$ & 0.43 & $0.76^{*}$ \\
\hline SO0809 & Azurin precursor $(a z u)$ & 0.44 & 0.69 & 0.28 & 0.84 & 0.3 & 0.4 \\
\hline SO3034 & Ferric iron reductase protein, putative & $1.09 *$ & 0.61 & $0.91 *$ & 0.25 & 0.45 & 0.42 \\
\hline SO4I5I & Polysaccharide deacetylase family protein & 0.29 & 0.3 & 0.35 & 0.6 & 0.24 & 0.23 \\
\hline SO4503 & Formate dehydrogenase accessory protein FdhD & $1.13 *$ & 0.56 & 0.53 & 0.5 & 0.28 & 0.36 \\
\hline SO4506 & Iron-sulfur cluster-binding protein & 0.42 & 0.28 & 0.77 & 0.45 & 0.47 & 0.39 \\
\hline SO4509 & Formate dehydrogenase, alpha subunit & 0.4 & 0.29 & 0.63 & 0.38 & 0.23 & 0.37 \\
\hline
\end{tabular}

\section{Hypothetical}

\begin{tabular}{|c|c|c|c|c|c|c|c|}
\hline SOA0058 & Hypothetical protein & 1.19 & $0.82 *$ & $1.0 *$ & $0.37^{*}$ & 0.29 & 0.27 \\
\hline SO0496 & Conserved hypothetical protein & 0.59 & 0.4 & 0.48 & 0.45 & 0.46 & $0.66^{*}$ \\
\hline SOII88 & Conserved hypothetical protein & 0.01 & 0.013 & 0.007 & 0.006 & 0.004 & $1.52 *$ \\
\hline SOII89 & Conserved hypothetical protein & 0.003 & 0.022 & 0.006 & 0.004 & 0.005 & $1.68^{*}$ \\
\hline SOII90 & Conserved hypothetical protein & 0.01 & 0.014 & 0.02 & 0.009 & 0.02 & $1.03 *$ \\
\hline SOI770 & Glycerate kinase, putative & 0.56 & 0.48 & 0.35 & 0.18 & 0.22 & $0.72^{*}$ \\
\hline SOI967 & Hypothetical protein & $0.97^{*}$ & $0.78^{*}$ & 0.34 & $0.55^{*}$ & 0.72 & 0.42 \\
\hline $\mathrm{SO} 2128$ & Hypothetical protein & 0.38 & 0.43 & 0.32 & 1.21 & 0.54 & $0.89 *$ \\
\hline SO2425 & Hypothetical protein & 0.21 & 0.29 & 0.23 & 0.09 & 0.14 & $1.63^{*}$ \\
\hline SO2469 & Conserved hypothetical protein & 0.35 & 0.53 & 0.68 & 0.62 & 0.46 & $0.96 *$ \\
\hline SO3025 & Conserved hypothetical protein & 0.17 & 0.16 & 0.16 & 0.2 & 0.23 & $0.73^{*}$ \\
\hline SO3062 & Hypothetical protein & 0.48 & 0.15 & 0.16 & 0.14 & 0.21 & $1.21 *$ \\
\hline SO4502 & Conserved domain protein & $0.93 *$ & $0.74^{*}$ & 0.54 & $0.54^{*}$ & 0.26 & 0.3 \\
\hline SO4504 & Conserved hypothetical protein & 0.2 & 0.06 & 0.15 & 0.14 & 0.23 & 0.13 \\
\hline SO4505 & Conserved hypothetical protein & 0.23 & 0.16 & 0.45 & 0.23 & 0.29 & 0.16 \\
\hline SO4689 & Conserved hypothetical protein & 0.51 & 0.43 & 0.4 & 0.45 & 0.54 & $0.76^{*}$ \\
\hline SO4719 & Conserved hypothetical protein & 0.23 & 0.36 & 0.36 & 0.31 & 0.18 & $0.62^{*}$ \\
\hline
\end{tabular}

\section{Protein synthesis}

\begin{tabular}{|c|c|c|c|c|c|c|c|}
\hline SO0106 & Selenocysteine-specific translation elongation factor (selB) & 0.38 & $0.72^{*}$ & 0.57 & $0.76^{*}$ & 0.46 & $0.83^{*}$ \\
\hline \multicolumn{8}{|c|}{ Regulatory functions } \\
\hline SO0916 & Transcriptional regulator, MarR family & 0.64 & 0.42 & 0.4 & 0.34 & 0.33 & $0.84^{*}$ \\
\hline SO0544 & Sensory box histidine kinase & 0.53 & 0.31 & 0.35 & 0.51 & 0.52 & $0.58^{*}$ \\
\hline SO4477 & Transcriptional regulatory protein $\mathrm{CpxR}(c p \times R)$ & 0.54 & 0.32 & 0.37 & 0.35 & 0.43 & $0.89 *$ \\
\hline SO4567 & Transcriptional regulator, AsnC family & 0.41 & 0.39 & 0.44 & 0.79 & 0.34 & 0.45 \\
\hline
\end{tabular}

\section{Transport and binding proteins}

\begin{tabular}{llllllll}
\hline SO0139 & Ferritin $(f t n)$ & 0.2 & 0.22 & 0.11 & 0.08 & 0.05 & 0.19 \\
SOI580 & TonB-dependent heme receptor & 0.32 & 0.39 & 0.37 & 0.19 & 0.23 & $0.92^{*}$ \\
SOI771 & Permease, GntP family & $0.88^{*}$ & 0.23 & 0.43 & 0.37 & 0.14 & 0.2
\end{tabular}


Table I: Selected genes with down-regulated expression profiles in the $\Delta$ so2426 mutant relative to wild-type MR-I (Continued)

\begin{tabular}{llllllll}
\hline SO2045 & Cation efflux family protein & 0.57 & 0.24 & 0.3 & 0.22 & 0.13 & $1.19^{*}$ \\
SO3030 & Siderophore biosynthesis protein AlcA (alcA) & 0.67 & 0.27 & $0.8 I^{*}$ & 0.21 & 0.15 & $0.69^{*}$ \\
SO3031 & Siderophore biosynthesis protein, putative & 0.52 & 0.34 & 0.3 & 0.16 & 0.08 & $1.37^{*}$ \\
SO3032 & Siderophore biosynthesis protein, putative & 0.5 & 0.33 & 0.25 & 0.14 & 0.06 & $0.73^{*}$ \\
SO3033 & Ferric alcaligin siderophore receptor & 0.73 & 0.34 & 0.29 & 0.17 & 0.07 & $0.77^{*}$ \\
SO3063 & Sodium:alanine symporter family protein & 0.26 & 0.18 & 0.12 & 0.15 & 0.18 & 0.34 \\
SO4150 & Transporter, putative & 0.07 & 0.12 & 0.11 & 0.34 & 0.27 & 0.3 \\
SO4516 & Ferric vibriobactin receptor (viuA) & 0.59 & 0.54 & 0.37 & 0.21 & 0.16 & $0.67^{*}$ \\
SO47I2 & ABC transporter, ATP-binding protein, putative & 0.49 & $0.84^{*}$ & 0.59 & $0.77^{*}$ & 0.54 & $0.59^{*}$ \\
SO4743 & TonB-dependent receptor, putative & 0.08 & 0.16 & 0.09 & 0.06 & 0.05 & 0.43 \\
& & & & & & &
\end{tabular}

tThe mRNA ratios ( $\Delta$ so2426 mutant/wild type) per time interval represent mean values derived from six DNA microarray experiments performed with total RNA isolated from three independent cultures (plus two dye reversal reactions per biological replicate) in chromate-amended LB medium.

*Expression ratio values determined to be statistically non-significant $(p>0.05)$.

downstream genes (so3031 and so3032, respectively) diverge from alcB and alc $\mathrm{C}$ and are annotated as putative siderophore biosynthesis genes. While the structural identity of the MR-1 siderophore has not been elucidated, we predict that MR-1 likely produces a siderophore similar to putrebactin [38], a novel cyclic dihydroxamate siderophore characterized from Shewanella putrefaciens strain 200 and structurally similar to alcaligin.

Consistent with the transcriptomic data, further physiological evidence for the involvement of the SO2426 response regulator in controlling siderophore-dependent iron acquisition was obtained by performing semiquanti- tative liquid CAS assays in which relative siderophore production levels in supernatants of the $\Delta s 02426$ mutant were compared to those in wild-type MR-1 cultures. Following 24-h growth in $\mathrm{LB}$ medium in the absence of added $\mathrm{FeCl}_{3}$ or chromate, the $\Delta s 02426$ mutant $\left(A_{630}, 0.739 \pm 0.02\right)$ exhibited essentially no detectable siderophore production over that of the cell-free control $\left(A_{630}, 0.726 \pm 0.005\right)$, whereas wild-type MR- 1 cultures $\left(A_{630}, 0.108 \pm 0.06\right)$ produced approximately 7 -fold more siderophore than the $\Delta s o 2426$ mutant. As expected, addition of $50 \mu \mathrm{M} \mathrm{FeCl}_{3}$ to the culture medium reduced siderophore production by the wild-type to near background levels (an approximately 6-fold reduction) but did not affect siderophore

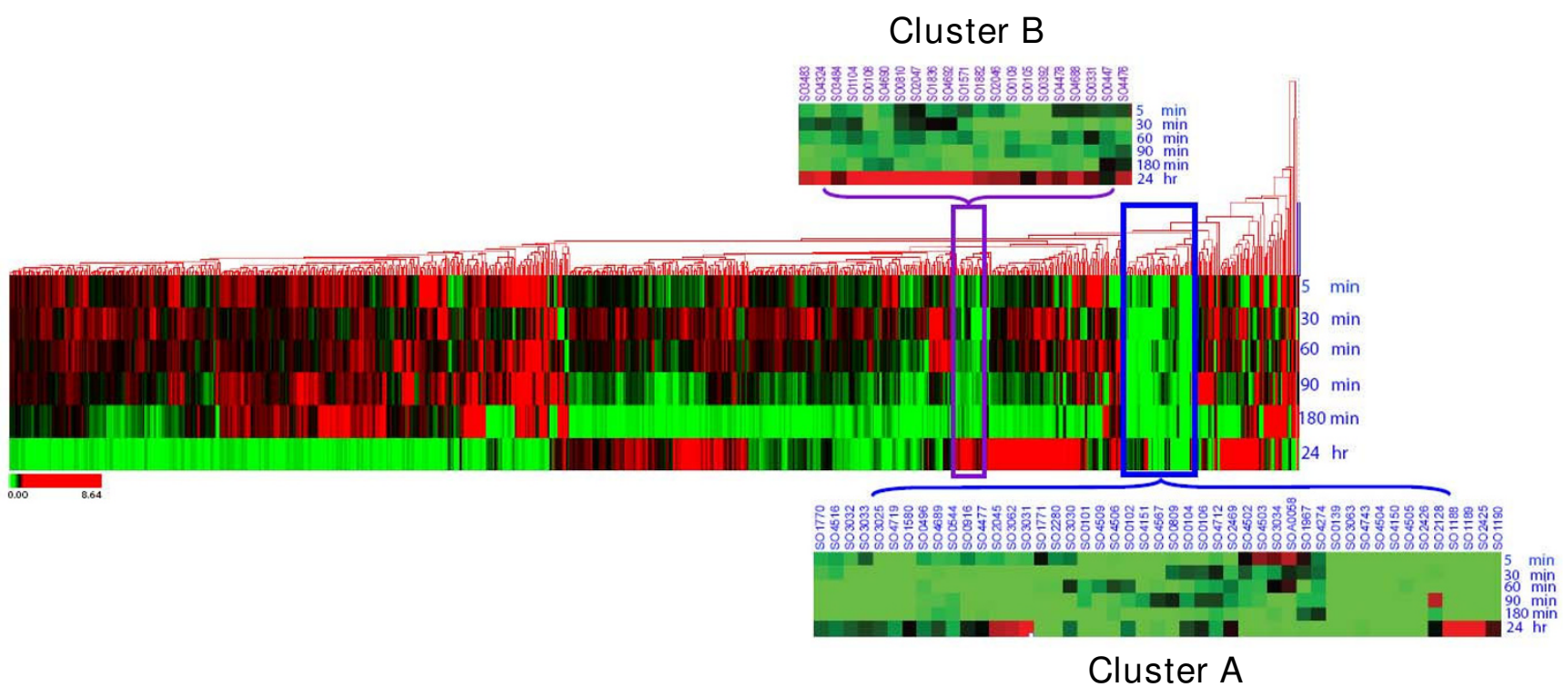

Figure 5

Complete linkage clustering analysis of genes with altered expression profiles in the $\Delta$ so2426 mutant. The $84 \mathrm{I}$ genes (out of the 4,648 represented on the microarray) exhibiting at least a twofold statistically significant $(p<0.05)$ change in expression for at least one of the time points during $\mathrm{Cr}(\mathrm{VI})$ exposure were analyzed by pairwise complete-linkage clustering. Transcriptional profiles are shown at 5, 30, 60, 90, $180 \mathrm{~min}$, and $24 \mathrm{~h}$ post chromate addition. Individual genes are represented by a single row, and each exposure time interval is represented by a single column. Red represents induction, while green represents repression. Two noteworthy clusters (A and B) are indicated, with their respective expression heat maps enlarged. 
accumulation in the $\Delta s 02426$ mutant. In the presence of $0.3 \mathrm{mM}$ chromate, replicate cultures of wild-type MR-1 exhibited increasing levels in relative siderophore production over time (Figure 6), which was consistent with previous microarray expression data showing induction of siderophore biosynthesis genes in response to chromate exposure [11]. By contrast, the temporal profile for the $\Delta s o 2426$ mutant showed an initial moderate increase and then a dramatic reduction in siderophore excretion compared to the wild type (Figure 6). Collectively, these data support the hypothesis that $\mathrm{SO} 2426$ is a positive regulator of siderophore-mediated Fe uptake.

Cluster A also includes an S. oneidensis gene that is involved in Fe storage, i.e., the ftn gene (so0139) encoding ferritin. The $f t n$ mRNA expression levels were down-regulated 4- to 20-fold in the SO2426 null mutant across the entire temporal range, with the peak in repression occurring at the 180 -min time point (Table 1 ). Although iron is an essential micronutrient for most organisms, free excess $\mathrm{Fe}$ in the presence of oxygen is potentially toxic because of its tendency to participate in Fenton chemistry reactions, which generate cell-damaging reactive oxygen intermediates. By scavenging and storing intracellular free $\mathrm{Fe}$ in a

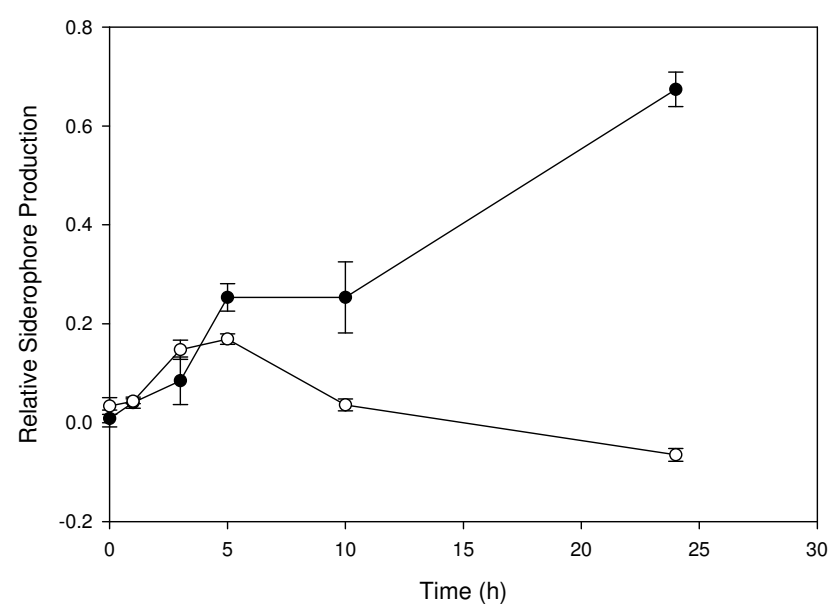

\section{Figure 6}

Relative siderophore production by wild-type MR-I and $\Delta$ so2426 mutant cells under chromate conditions. A final chromate concentration of $0.3 \mathrm{mM}$ was added to midlog-phase $\left(O D_{600}, 0.5\right)$ wild-type $M R$-I (O) and $\Delta$ so2426 mutant $(O)$ cultures cultivated in LB broth, and relative siderophore synthesis by each culture was monitored over time using the CAS assay. The relative siderophore production was calculated by subtracting the supernatant $A_{630}$ for the wild type or mutant from the uninoculated control and then determining the ratio of corrected supernatant $A_{630}$ to control $A_{630}$. The graphed values represent mean ratios \pm standard errors (bars) for three replicate CAS measurements. remobilizable form, Ftn protects against $\mathrm{Fe}(\mathrm{II})$-mediated formation of hydroxyl radicals $[39,40]$. Studies have indicated that ferritins make important contributions to both Fe storage as well as cellular protection against oxidative stress $[41,42]$ and that $f t n$ transcription is co-ordinately regulated by iron and redox stress in some bacteria [43]. $S$. oneidensis $f t n$ was shown previously to be induced at a low level ( $\sim$-fold) in chromate-exposed wild-type MR-1 cells in contrast to untreated cells [11]. The induction of $\mathrm{ftn}$ in S. oneidensis might act, at least partially, to mitigate chromate-generated oxidative stress by sequestering excess free Fe available for the catalysis of Fenton reactions and the formation of additional reactive hydroxyl radicals.

\section{Genes of unknown function}

The majority of coordinately repressed genes in Cluster A belong to the functional category of hypothetical and conserved hypothetical proteins (Table 1). Most notably, genes comprising the conserved hypothetical so1188so1189-so1190 operon exhibited the highest degree of down-regulated expression in the chromate-exposed $\Delta$ so2426 mutant relative to the wild type, with decreases in mRNA ratios ranging from 45 - to $>300$-fold over the 180 min period. No significant changes in expression, however, were observed for these genes at the 24-h time point. In addition, the hypothetical gene so2425, which is cotranscribed with so2426 in a polycistronic transcript (shown in this study), was repressed as much as 11 -fold over the 180-min period, pointing to the possibility that the so2426 operon may be under positive autoregulatory control. Surprisingly, the functionally unknown genes so2424, so2423, and so2422, which also form part of the so2426 operon, showed either a less than 2-fold change or no significant differential expression over the time course.

\section{Regulatory genes}

In addition to metal transport and hypothetical genes described above, the temporal expression profiles for four transcriptional regulatory genes (so0916, so0544, cpxR, so4567) were altered in the $\Delta s 02426$ mutant. The function of the regulators encoded by so0916, so0544, and s04567 in S. oneidensis as well as their target genes are not known. However, gene so4477 encodes a homolog of CpxR, the response regulator component of the CPxAR envelope stress response system, which has been well characterized in E. coli (reviewed in $[35,44]$ ). The annotated $c p x R$ gene in S. oneidensis MR-1 was downregulated as much as threefold in response to the so2426 deletion under chromate stress conditions (Table 1). This is in contrast to the twoto three-fold induction measured for $c p x R$ in chromatetreated wild-type MR-1 cells [11]. Located immediately downstream of $c p x R$ in an apparent operon is $c p x A$, which was downregulated as much as 3 -fold in the mutant but grouped in a separate cluster (Cluster B in Figure 5). 
In E. coli, the CpxAR two-component pair constitutes a stress response system the main function of which is to sense and respond to cell envelope distress, principally misfolded periplasmic proteins, by activating genes encoding proteases and folding catalysts $[35,45,46]$. However, the complexity, extent, and response overlap of the Cpx system have become progressively apparent, as evident from its involvement in outer membrane porin expression [47], stationary-phase survival [48], and the response to high $\mathrm{pH}$ stress [49] to name a few. Although the specific cellular role of the CpxR homolog in S. oneidensis has not been established, it is intriguing to consider the possibility that interplay between CpxR and SO2426 may occur in response to metal stress. It is conceivable that the CpxA-CpxR two-component system may respond to oxidative damage imposed on biomolecules as a consequence of reactive oxygen species generated during intracellular partial $\mathrm{Cr}(\mathrm{VI})$ reduction.

\section{Other differentially regulated genes in the so2426 deletion mutant}

While hypothetical and metal transport/binding genes are dominant in Cluster A (representing 65\%), other notable genes with $\geq 2$-fold-repressed mRNA levels in the $\Delta s o 2426$ mutant include ORFs codifying a putative bicyclomycin resistance (Bcr) protein (SO2280) and a ferric iron reductase protein (SO3034). Bcr proteins are members of the major facilitator superfamily class of membrane efflux pumps and play important roles in drug resistance [50]. In a previous work, the so2280 gene in a wild-type MR-1 genetic background exhibited 2- to 4-fold upregulated expression at the transcript level in response to short-term chromate exposure, i.e., up to 90 min [11], but was shown in this study to be repressed as much as 4-fold in $\mathrm{Cr}(\mathrm{VI})$ challenged $\Delta$ so2426 cells (Table 1 ), suggesting that the so2280 gene is a direct or indirect target of SO2426-mediated activation under chromate conditions. Although the cellular function of SO2280 is presently unknown, its coordinately regulated expression with the siderophore biosynthesis operon (alcA-so3031-so3032) and gene so3033, encoding a ferric alcaligin siderophore receptor, is intriguing. Studies in other bacterial systems have shown that certain proteins resembling Bcr at the amino acid level function in siderophore export from the cell [51].

Downregulated expression of gene so3034 (a putative ferric iron reductase) peaked at the $90-$ min time point with a 4-fold decrease in mRNA levels (Table 1). Ferric iron reductases are thought to be involved in reducing siderophore-complexed $\mathrm{Fe}(\mathrm{III})$ to $\mathrm{Fe}(\mathrm{II})$, thus enabling dissociation of the high-affinity $\mathrm{Fe}^{3+}$-chelating siderophore from iron [30]. The entire so3030-so3034 gene cluster, which is predicted to be involved in siderophore production and utilization, exhibits similar temporal expression profiles in the mutant, suggesting a role for the SO2426 response regulator in coordinating these functions. It is not clear whether the other differentially expressed energy metabolism genes ( $f d h G, f d n H$, fdhE, so4503, so4506, so4509) contribute directly to chromate stress response or show altered transcription as a result of secondary effects associated with the so2426 deletion. These genes were not observed to be induced in response to chromate exposure in our previous transcriptomic studies using wild-type $S$. oneidensis MR-1 [11].

\section{Conclusion}

S. oneidensis SO2426 is an apparent orphan response regulator with an N-terminal domain that contains an aspartate residue at the canonical receiver phosphorylation site and a predicted C-terminal wHTH motif indicative of response regulators in the OmpR subfamily. Although previous work in this laboratory demonstrated enhanced mRNA levels for the so2426 gene in a S. oneidensis Fur-deficient strain [31] and in chromate-challenged wild-type MR-1 cells [11], the basic molecular function of this predicted transcriptional regulator remained undefined. In this study, by integrating functional genomics and genetic approaches, we have shown that SO2426 is a direct or indirect positive regulator of siderophore-mediated $\mathrm{Fe}$ transport systems, the Fe storage gene $\mathrm{ftn}$, and other as-yet uncharacterized cation transport genes. At this time, however, we cannot discount the possibility of negative regulation by SO2426 as well. Clustering analysis of temporal transcriptome data revealed a distinctive subset of 46 coordinately expressed genes that were consistently downregulated in the so2426 deletion mutant during the initial 180-min period of chromate exposure. Many of these genes - namely, ftn, the alcA-so3031-so3032 siderophore biosynthesis operon, so1580 (TonB-dependent heme receptor), so4743 (TonB-dependent receptor), viuA, so2280 (bcr), as well as a number of hypothetical genes - constituted the predominant molecular response to acute chromate stress in wild-type MR-1 [11]. The transcriptomic analyses described here identified a number of possible directly SO2426-regulated genes, including those of unknown function, that may serve as targets for future studies.

One possible hypothesis that can be generated from the collective data described here is that $S$. oneidensis MR-1 employs at least two control mechanisms for regulating $\mathrm{Fe}$ acquisition via siderophores under conditions of external Fe insufficiency: derepression as a result of decreased Fur activity and activation by SO2426 to enhance needed expression of $\mathrm{Fe}$ (III) transport systems. CAS siderophore assays clearly demonstrated that the $\Delta s o 2426$ mutant was deficient in siderophore production compared to wildtype MR-1 cultures in the presence and absence of chromate, indicating that SO2426 plays a positive role in coordinating the regulation of siderophore-dependent $\mathrm{Fe}$ 
uptake mechanisms in $S$. oneidensis. Furthermore, the impaired chromate reduction rate of the so2426 deletion strain points to a connection between Fe transport and chromate stress response that requires further delineation at the molecular level. Our previous global studies characterizing the transcriptome and proteome of wild-type MR1 in response to sub-lethal acute doses of chromate demonstrated a dramatic and unexpected induction of genes involved in Fe sequestration and uptake in contrast to unchallenged cells $[11,13]$. Two possible explanations for this observation are (i) Fe limitation under external chromate conditions, and (ii) direct or indirect displacement of the $\mathrm{Fe}(\mathrm{II})$ cofactor from Fur-binding sites under elevated $\mathrm{Cr}(\mathrm{VI})$, resulting in decreased DNA-binding activity of the Fur repressor and subsequent derepression of target genes. Exposure to other metals has been shown to perturb intracellular Fe pools and hence influence Fur-mediated repression [52]. Future studies will focus on experimentally confirming direct gene targets of SO2426 control and further elucidating the linkage between regulation of $\mathrm{Fe}$ homeostasis and chromate stress response at molecular and physiological levels.

\section{Methods}

Bacterial strains, plasmids, and growth conditions

All bacterial strains and plasmids used in this study are listed in Table 2. S. oneidensis strain MR-1 [4,53] was used as the wild type. The $\Delta s o 2426$ strain, a derivative of MR-1, contains an in-frame deletion of the so2426 locus on the chromosome (see below for a detailed description of mutant construction). For growth studies, wild-type and mutant strains were cultivated aerobically with shaking (250 rpm) at $30^{\circ} \mathrm{C}$ in Luria-Bertani (LB) medium (pH 7.2) alone or in media amended with $0.3 \mathrm{mM}$ (final concentration) of $\mathrm{K}_{2} \mathrm{CrO}_{4}$. Optical density was monitored at a wavelength of $600 \mathrm{~nm}\left(\mathrm{OD}_{600}\right)$ in triplicate using either a Spectronic 20D+ spectrophotometer (Thermo Electron Cooperation, Waltham, MA) or the Bioscreen C microbiological culture system (Growth Curves USA, Piscataway, NJ) as described elsewhere [36].

For transcriptome analyses, three separate batch cultures each of wild-type MR-1 and the $\Delta s o 2426$ mutant were grown to mid-exponential phase $\left(\mathrm{OD}_{600}, 0.5\right)$ in $100 \mathrm{ml}$ of LB broth, followed by addition of $2 \mathrm{M} \mathrm{K}_{2} \mathrm{CrO}_{4}$ to a final concentration of $0.3 \mathrm{mM}$. The two different sets of chromate-challenged cultures (wild type and mutant), each consisting of three biological replicates, were grown aerobically in parallel at $30^{\circ} \mathrm{C}$. Cells were harvested for RNA extraction at 5, 30, 60, 90, $180 \mathrm{~min}$, and $24 \mathrm{~h}$ post-chromate exposure. For RT-PCR and 5' RACE experiments, wild-type $S$. oneidensis MR-1 cells were grown to mid-log phase $\left(\mathrm{OD}_{600}, 0.5\right)$ in LB broth at $30^{\circ} \mathrm{C}$ and then exposed to chromate (final concentration, $1 \mathrm{mM}$ ) for $30 \mathrm{~min}$ before harvesting cells for RNA extraction. Untreated MR1 cells were grown in parallel and used as the control.

\section{Chromate reduction and CAS siderophore assays}

Disappearance of extracellular Cr(VI) was quantified spectrophotometrically using the 1,5-diphenylcarbazide (DPC) method as described elsewhere [34]. Cultures were assayed at different time points $(5,30,60,90,180 \mathrm{~min}$, and $24 \mathrm{~h}$ ) post chromate-challenge to determine the amount of residual $\mathrm{Cr}$ (VI) remaining in the medium by measuring absorbance at $540 \mathrm{~nm}$ using a Varian (Cary1E) UV-visible spectrophotometer (Hewlett-Packard, Wilmington, DE). Cell-free LB medium containing 0.3 $\mathrm{mM} \mathrm{K}_{2} \mathrm{CrO}_{4}$ served as the abiotic negative control and was monitored in parallel with the experimental samples.

The chrome azurol S (CAS) assay for detection of siderophore production was performed essentially as

Table 2: Bacterial strains and plasmids used in this study

\begin{tabular}{|c|c|c|}
\hline Strain or plasmid & Relevant characteristics & Source or reference \\
\hline \multicolumn{3}{|l|}{ Strains } \\
\hline \multicolumn{3}{|l|}{ S. oneidensis } \\
\hline MR-I (ATCC 700550) & Wild type & Laboratory Stock \\
\hline$M R-I / \Delta s o 2426$ & In-frame deletion of the so2426 locus & This study \\
\hline MR-I/Aso2426(so2426+) & $\Delta$ so2426 mutant complemented with pBBRso 2426 & This study \\
\hline E. coli WM3064 & DAP-auxotrophic wild type & [32] \\
\hline \multicolumn{3}{|l|}{ Plasmids } \\
\hline PJKI00 & Allelic-exchange vector & [32] \\
\hline PJKI02 & pJK 100 with so2426 upstream and downstream regions & This study \\
\hline pCMI57 & Cre recombinase expression vector & [32] \\
\hline PBBRIMCS-5 & $\mathrm{Gm}^{\mathrm{r}}$, broad-host range vector, lacPOZ' & {$[56]$} \\
\hline PBBRso2426 & PBBR IMCS5-based construct harboring entire so 2426 gene & This study \\
\hline
\end{tabular}


described by Schwyn and Neilands [54]. Siderophore biosynthesis and excretion by the $\Delta s o 2426$ mutant was compared with those by the wild-type MR-1 strain in LB broth with or without the addition of $50 \mu \mathrm{M} \mathrm{FeCl}_{3}$ or $0.3 \mathrm{mM}$ $\mathrm{K}_{2} \mathrm{CrO}_{4}$. Cultures of these strains were grown aerobically to stationary phase $\left(\mathrm{OD}_{600}>1.0\right)$ at $30^{\circ} \mathrm{C}$ for $24 \mathrm{~h}$. Cellfree supernatants of $S$. oneidensis cultures were mixed 1:1 with the CAS assay solution and equilibrated at room temperature for $2 \mathrm{~h}$ before the absorbance at $630 \mathrm{~nm}$ was measured. The relative siderophore production was calculated as the ratio of the control (uninoculated LB medium) $A_{630}$ to the wild-type or mutant strain superna$\operatorname{tant} A_{630}$. All CAS measurements were performed in triplicate, and at least two independent determinations were conducted.

\section{Construction of an S. oneidensis so2426 deletion strain and complementation}

An S. oneidensis MR-1 in-frame deletion mutant lacking the so2426 locus was generated using the cre-lox recombination system as described elsewhere $[32,33]$. The application of this mutagenesis strategy to targeted S. oneidensis MR-1 genes has been described previously [55]. The primer sequences used in the generation and verification of the $\Delta$ so2426 mutant are listed in Table 3. PCR was used to amplify a 900-bp region upstream and a 840-bp region downstream of the so2426 gene using primer pairs Del900-F/Del900-R and Del840-F/Del840-R, respectively. The amplified regions were cloned into the kanamycin-resistant $\left(\mathrm{Km}^{\mathrm{r}}\right)$ plasmid pJK100 [32]. The resulting plasmid, pJK102, carrying a correct construct was introduced into the E. coli strain WM3064 [32], a diaminopimelic acid (DAP) auxotroph, and then subsequently moved into MR-1 via conjugation with WM3064. The resultant MR-1 strain was $\mathrm{Km}^{\mathrm{r}} / \mathrm{Tet}^{\mathrm{s}}$ and contained the loxP-Km $m^{r}$-loxP cassette. Removal of the kanamycin cassette and the helper plasmid was performed as described elsewhere [33]. A cre-recombinase enzyme-producing plasmid, pCM157/Tetr, was introduced into MR-1 to resolve the loxP-Kmr-loxP cassette through conjugation. The $\mathrm{Tet}^{\mathrm{r}}$ plasmid pCM157 was cured from MR-1 by continuous culturing in non-selective LB medium. The in-frame deletion of so2426 was confirmed by PCR amplification using several sets of primers (ISU2426/ISD2426, OP840, OP900, kanF/kanR in Table 3 ) and DNA sequencing.

The $\Delta$ so2426 mutant was complemented by reintroduction of the wild-type so2426 allele on a low-copy-number

Table 3: Oligonucleotide primers used in this study

\begin{tabular}{|c|c|c|}
\hline Primer & DNA sequence $\left(5^{\prime} \rightarrow 3^{\prime}\right)$ & Reference or source \\
\hline \multicolumn{3}{|c|}{ Construction of $\Delta s 02426$ strain } \\
\hline Del840-F & CTTGGTTACCGGCTAGTGAAC & This study \\
\hline Del840-R & GGCAGGTATTGATAACAATGA & This study \\
\hline Del900-F & GGTTCACACCAATCGCATTAG & This study \\
\hline Del900-R & TGGCCAATACCCGCTTACCGC & This study \\
\hline ISU2426 & GCCTAAGATGCCATCAGT & This study \\
\hline ISD2426 & TCTTCAAGATTTAGCTTATCC & This study \\
\hline OP840 & CACATAAGGCAGACCTTCGTC & This study \\
\hline OP900 & ATGGTCCGTACTGTGGCCGC & This study \\
\hline kanF & ATTGTTGATGCGCTGGCAGT & [32] \\
\hline $\operatorname{kanR}$ & TCCGGTGAGAATGGCAAAAG & [32] \\
\hline
\end{tabular}

\section{Construction of complementation plasmid}

\begin{tabular}{lll}
\hline $2426 \mathrm{com}-\mathrm{F}$ & ACACACAAGCTTGCGCTTTTCTTTTAGGTACAA & This study \\
$2426 \mathrm{com}-\mathrm{R}$ & ACACACGGATCCGACTCACAGAGGGCGCTTA & This study
\end{tabular}

RT-PCR analysis

\begin{tabular}{lll}
\hline PI & ATGATATTGATTCTCGTTTG & This study \\
P2 & CCGAGTGTGGTTAACTGATG & This study \\
P3 & CGCCGAGTATTACTGATATGC & This study \\
P4 & AAGCGCTAAAACTGTATCC & This study \\
P5 & TTAACATGCATCTACTTTTA & This study \\
P6 & GATCTTGCAGGTTGTTGTT & This study \\
P7 & TCATACACTCTTTCGCTTAT & This study \\
P8 & CTGTTTCTTCAACTCAGCCT & This study \\
P9 & CAGTCGTTAGCTCAATTGCT & \\
\hline
\end{tabular}


plasmid. For this, the so2426 open reading frame with 100 bp of upstream sequence was amplified from $S$. oneidensis MR-1 genomic DNA using primers 2426com-F and 2426 com-R (Table 3 ). The PCR product was gel purified, digested, and ligated into the Bam H1 and HindIII sites of the plasmid pBBR1MCS-5 [56], which contains a gentamicin resistance $\left(\mathrm{Gm}^{\mathrm{r}}\right)$ cassette. The resultant construct harboring the complete S. oneidensis so2426 gene with its endogenous promoter was designated pBB2426. The pBB2426 plasmid was electroporated into E. coli strain WM3064 and then introduced into the $S$. oneidensis $\Delta$ so2426 mutant and wild-type MR-1 strains via conjugation. In addition, plasmid pBBR1MCS5 without the insert (empty vector) was also transferred into the mutant and wild-type strains via conjugation with WM3064. $\mathrm{Gm}^{\mathrm{r}}$ Shewanella colonies were verified for the presence of the so2426 gene by PCR analysis and DNA sequencing.

\section{RNA isolation}

For microarray profiling and real-time RT-PCR experiments, total cellular RNA was isolated from S. oneidensis cultures using the TRIzol reagent (Invitrogen, Carlsbad, $\mathrm{CA}$ ) according to the manufacturer's instructions. RNA preparations were treated with RNase-free DNase I (Ambion Applied Biosystems, Foster City, CA) to remove residual genomic DNA and subsequently further purified using the RNeasy Mini Kit (Qiagen, Valencia, CA) according to the manufacturer's RNA cleanup protocol. Total RNA was quantitated as described previously [36]. For RTPCR and 5'-RACE analyses, total RNA was extracted from S. oneidensis cultures using the RNeasy Mini Kit (Qiagen). Chromosomal DNA contamination was removed by incubating total purified RNA with $3 \mathrm{U}$ of RNase-free DNase (Ambion Applied Biosystems) for $30 \mathrm{~min}$ at $37^{\circ} \mathrm{C}$. The DNA digestion reaction was performed twice for each RNA sample. The quantity and purity of the RNA was assessed as described previously [36]. The integrity of all RNA samples was assessed visually using $1 \%$ agarose gel electrophoresis and ethidium bromide staining.

\section{Microarray hybridizations and data analysis}

Transcriptome analyses were performed with a microarray containing 4,197 PCR amplicons and 451 specific 50-mer oligonucleotides, covering approximately $94 \%$ of the total predicted gene content of S. oneidensis MR-1. Fabrication of the MR-1 arrays has been described in detail elsewhere [57]. Synthesis of the two differentially labeled cDNA pools (wild-type MR- 1 and the $\Delta$ so2426 mutant) to be compared, microarray prehybridization and hybridization, and post-hybridization washings were performed as described previously [36]. Temporal gene expression analysis was performed using six independent microarray hybridizations (three biological replicates $\times$ two dye-swap reactions) for each of six time points, with each slide containing two spots representing each gene at different array locations for a total of 12 signal intensity measurements per gene per time point. Image quantification, data normalization, and analysis of gene expression data for statistical significance were conducted as described by Brown $e t$ al. [36]. The time-series microarray expression profiles of the $\Delta$ so2426 mutant relative to the parental strain were clustered using Hierarchical Clustering Explorer (HCE) [58]. During the clustering process, only genes with an expression value of at least $\geq 2$-fold or $\leq 0.5$-fold in one or more of 6 expression profiling time points were included in the analyses. As a result, a dataset of 841 genes was clustered based on average linkage using Euclidean distance.

\section{Access to microarray data}

The microarray data reported in this study have been deposited in MIAME-compliant format at Gene Expression Omnibus on the NCBI website [59] under series accession number GSE12129. The statistically analyzed microarray output is provided in Additional file 1.

\section{Quantitative real-time $R T-P C R$}

Reverse transcriptase, quantitative real-time PCR (qRTPCR) was used to provide an independent assessment of gene expression for five selected genes (so0404, so2426, so3670, so1826, and so3585), which exhibited different expression patterns (i.e., down-regulated or no change). These genes are predicted to encode a hypothetical protein (SO0404), a DNA-binding response regulator (SO2426), proteins involved in transport and binding of cations (SO3670 and SO1826), and a putative azoreductase (SO3585). Relative expression patterns for each selected gene were independently confirmed using the following primer pairs, which were designed using the program Primer3 http://www-genome.wi.mit.edu/cgi-bin/ primer/primer3 www.cgi: SO0404, 5'-AGTATAACCAAGCGCCAGTA and 3'-GCATCGGTATTAACTTGCTC; SO2426, 5'-GCAGAAGGATTTAGGTCGAT and 3'-CGGTGTTGATTAAAGTACGC; SO3670， 5'-TCTAAACAGTCGCAGGAGCA and 3'-GCGCCATATTGCTATCCATT; SO1826, 5'-GGGTGTCCCAAGCTAGT CAA and 3'-GAGCATTACTCGTCCCCTGA; SO3585， 5'-CGAGGCTATCCATC ACTTAG and 3'-TGGAAAACACGATAAAGACC. Reverse transcription was performed on the 180-min time point samples with $3 \mu \mathrm{g}$ of total cellular RNA and $2.5 \mathrm{mM}$ random hexamers using Superscript ${ }^{\mathrm{TM}}$ II RNase H- Reverse Transcriptase (Invitrogen) as described previously [31]. Quantitative PCR was carried out in an iCycler $\mathrm{iQ}^{\oplus}$ realtime PCR system (BioRad, Hercules, CA) in 50- $\mu$ l reaction mixtures containing $1 \mu \mathrm{l}$ cDNA, $600 \mathrm{nM}$ forward and reverse primers, and iQ SYBR green supermix (BioRad) according to the manufacturer's instructions and conducted under the following conditions: $30 \mathrm{sec}$ at $95^{\circ} \mathrm{C}$, followed by 40 cycles of $15 \mathrm{sec}$ at $95^{\circ} \mathrm{C}, 30 \mathrm{sec}$ at the specific annealing temperature, and $30 \mathrm{sec}$ at $72^{\circ} \mathrm{C}$. The qRTPCR reactions were performed in triplicate for each of the 
three biological replicates tested. Standards for each gene of interest were included in the analysis as described previously [31]. The final $\Delta s o 2426 / \mathrm{WT}$ ratio for each target gene and the standard error were calculated as described elsewhere [31], and the linear correlation between the qRT-PCR and microarray data was determined based on the log mean values using Sigma-Plot version 9.0 (SPSS Inc., Chicago, IL).

\section{RT-PCR and 5'-RACE analyses}

Reverse transcription-PCR (RT-PCR) was performed to investigate the transcription of the so2427-so2422 gene cluster on the MR-1 chromosome. First-strand CDNA was synthesized from $1 \mu \mathrm{g}$ of DNase-treated total RNA isolated from MR-1 cultures grown in LB broth under either non-stress (no chromate added) or chromate stress (1 $\mathrm{mM}$, 30-min exposure) conditions. Random hexamers (250 ng), dNTPs $(10 \mathrm{mM}), 5 \times$ First-Strand buffer $(4 \mu \mathrm{l})$, $0.1 \mathrm{M}$ DTT $(1 \mu \mathrm{l})$, RNaseOUT $(1 \mu \mathrm{l})$, recombinant RNase inhibitor $(40 \mathrm{U})$, and Superscript ${ }^{\mathrm{TM}}$ II Reverse Transcriptase (200 U; Invitrogen) were added to the reaction mixture, which was incubated at $25^{\circ} \mathrm{C}$ for $10 \mathrm{~min}, 42^{\circ} \mathrm{C}$ for $50 \mathrm{~min}$, and then $70^{\circ} \mathrm{C}$ for $15 \mathrm{~min}$ in accordance with the recommendations of the supplier. Synthesized cDNA was used as the template in subsequent PCR amplification reactions with gene-specific oligonucleotide primers $\mathrm{P} 1-$ P9 (Table 3) spanning the so2427-so2422 gene region. The TripleMaster PCR System (Eppendorf, Westbury, NY) was used for amplification, with primers added to each reaction mixture at a final concentration of $250 \mathrm{nmol}$. The reaction mixtures were subjected to 30 cycles of denaturation at $94^{\circ} \mathrm{C}$ for $60 \mathrm{~s}$, annealing at $44-52^{\circ} \mathrm{C}$ (depending on the primer $\mathrm{T}_{\mathrm{m}}$ ) for $60 \mathrm{~s}$, and an extension at $72^{\circ} \mathrm{C}$ for 1-2 min in an Eppendorf Mastercycler ep gradient thermocycler. Each amplified product was analyzed by $1 \%$ agarose gel electrophoresis with ethidium bromide staining. In addition, each PCR product obtained was cloned into the pGEM-T vector (Promega, Madison, WI) and sequenced at Purdue University's Low-Throughput DNA Sequencing Laboratory to confirm that they were the expected loci of each respective gene region.

The transcriptional start site of the so2426 gene was localized using the 5' RACE System for Rapid Amplification of cDNA Ends version 2.0 (Invitrogen) according to the manufacturer's instructions. Briefly, cDNA was generated using Superscript ${ }^{\mathrm{TM}} \mathrm{II}$ reverse transcriptase $\left(42^{\circ} \mathrm{C}, 1 \mathrm{~h}\right.$; Invitrogen) in a reaction containing $2 \mu \mathrm{g}$ of total cellular RNA (from non-stressed or chromate-stressed MR-1 cells) and a so2426-specific primer (2426-GSP1: 5'-TAACCGATTGAATTGTT-3'). Nested PCR was performed using two so2426-specific primers (2426-GSP2: 5'-TGCACTAACCGTCGCTCTATGGCCTGCAAA-3' and 2426-GSP3: 5'GCACCAAGTTCATAGCTTCGTATCCTGTCT-3') and the manufacturer-supplied abridged anchor and abridged universal anchor primers. The 5'-RACE products were analyzed by agarose gel electrophoresis and cloned into the pGEM-T vector (Promega) prior to DNA sequencing.

\section{Authors' contributions}

KC created the deletion mutant analyzed in this work; performed the microarray experiments, qRT-PCR verifications, and the initial data analysis; and carried out the growth studies and $\mathrm{Cr}(\mathrm{VI})$ reduction assays. WW performed the operon structure analysis, transcription start site determination, and CAS siderophore assays. X-FW carried out statistical and clustering analyses of the microarray data. KC and X-FW both contributed to the manuscript writing. DKT conceived and coordinated the study and performed the majority of the manuscript writing. All authors read and approved the final manuscript.

\section{Additional material}

\section{Additional file 1}

Complete processed microarray dataset for the $\mathrm{S}$. oneidensis $\Delta$ so2426 mutant compared to the wild type under chromate conditions. This file provides the complete statistically analyzed microarray output for all six time points $(5,30,60,90,180 \mathrm{~min}$, and $24 \mathrm{~h})$ during chromate $(0.3 \mathrm{mM})$ exposure starting with the Gene ID, mean $\Delta$ so2426 mutant/WT expression ratio, n (number of signal values out of 12 total per gene included in the statistical analysis), statistical significance, gene name, gene product, main role category, and subrole category. ArrayStat ${ }^{\mathrm{TM}}$ (Imaging Research, Inc., Ontario, Canada) was used to determine the common error of normalized expression values, remove outliers, and determine statistical significance via a $\mathrm{z}$ test for two independent conditions and the false discovery rate method (nominal $\alpha$, confidence cutoff of $\mathrm{p}<$ 0.05).

Click here for file

[http://www.biomedcentral.com/content/supplementary/14712164-9-395-S1.zip]

\section{Acknowledgements}

We thank Dr. Joel Klappenbach for plasmids and E. coli strain WM3064 used in site-directed mutagenesis and Dr. Steven Brown for assistance with the construction of the so2426 deletion mutant. We also thank Drs. Jizhong Zhou and Liyou Wu for S. oneidensis MR-I microarrays, and Dr. Gene Wickham for helpful comments concerning the manuscript. This research was supported in part by the Office of Science (BER), U. S. Department of Energy, Grant No. DE-FG02-06ER64I63, to DKT.

\section{References}

I. Lovley DR, Holmes DE, Nevin KP: Dissimilatory Fe(III) and Mn(IV) reduction. Adv Microb Physiol 2004, 49:219-286.

2. Lovley DR, Phillips EJP, Gorby YA, Landa ER: Microbial reduction of uranium. Nature 1991, 350:413-416.

3. Moser DP, Nealson KH: Growth of the facultative anaerobe Shewanella putrefaciens by elemental sulfur reduction. Appl Environ Microbiol 1996, 62:2100-2105.

4. Myers $\mathrm{CR}$, Nealson $\mathrm{KH}$ : Bacterial manganese reduction and growth with manganese oxide as the sole electron acceptor. Science 1988, 240:|319-132|.

5. Myers CR, Nealson KH: Respiration-linked proton translocation coupled to anaerobic reduction of manganese(IV) and 
iron(III) in Shewanella putrefaciens MR-I. J Bacteriol 1990 172:6232-6238.

6. Middleton SS, Bencheikh-Latmani R, Mackey MR, Ellisman MH, Tebo BM, Criddle CS: Cometabolism of $\mathrm{Cr}(\mathrm{VI})$ by Shewanella oneidensis MR-I produces cell-associated reduced chromium and inhibits growth. Biotechnol Bioeng 2003, 83:627-637.

7. Myers CR, Carstens BP, Antholine WE, Myers JM: Chromium(VI) reductase activity is associated with the cytoplasmic membrane of anaerobically grown Shewanella putrefaciens MR-I. J Appl Microbiol 2000, 88:98-106.

8. Viamajala S, Peyton B, Apel W, Petersen J: Chromate/nitrite interactions in Shewanella oneidensis MR-I: Evidence for multiple hexavalent chromium $[\mathrm{Cr}(\mathrm{VI})]$ reduction mechanisms dependent on physiological growth conditions. Biotechnol Bioeng 2002, 78:770-778.

9. Bencheikh-Latmani R, Williams SM, Haucke L, Criddle CS, Wu L, Zhou J, Tebo BM: Global transcriptional profiling of Shewanella oneidensis MR-I during $\mathbf{C r}(\mathbf{V I})$ and $\mathbf{U}(\mathbf{V I})$ reduction. Appl Environ Microbiol 2005, 71:7453-7460.

10. Heidelberg JF, Paulsen IT, Nelson KE, Gaidos EJ, Nelson WC, Read TD, Eisen JA, Seshadri R, Ward N, Methe B, Clayton RA, Meyer T, Tsapin A, Scott J, Beanan M, Brinkac L, Daugherty S, DeBoy RT, Dodson RJ, Durkin AS, Haft DH, Kolonay JF, Madupu R, Peterson JD, Umayam LA, White O, Wolf AM, Vamathevan J, Weidman J, Impraim M, Lee K, Berry K, Lee C, Mueller J, Khouri H, Gill J, Utterback TR, McDonald LA, Feldblyum TV, Smith HO, Venter JC, Nealson KH, Fraser CM: Genome sequence of the dissimilatory metal ionreducing bacterium Shewanella oneidensis. Nat Biotechnol 2002 , 20: III8-II23.

II. Brown SD, Thompson MR, VerBerkmoes NC, Chourey K, Shah M, Zhou J, Hettich RL, Thompson DK: Molecular dynamics of the Shewanella oneidensis response to chromate stress. Mol Cell Proteomics 2006, 5: 1054-1071.

12. Chourey K, Thompson MR, Morrell-Falvey J, VerBerkmoes NC, Brown SD, Shah M, Zhou J, Doktycz M, Hettich RL, Thompson DK Global molecular and morphological effects of 24-hour chromium(VI) exposure on Shewanella oneidensis MR-I. Appl Environ Microbiol 2006, 72:633।-6344.

13. Thompson MR, VerBerkmoes NC, Chourey K, Shah M, Thompson DK, Hettich RL: Dosage-dependent proteome response of Shewanella oneidensis MR-I to acute chromate challenge. J Proteome Res 2007, 6: I745-1757.

14. James BR: The challenge of remediating chromium-contaminated soil. Environ Sci Technol 1996, 30:A248-A251.

15. Langard S: Chromium. In Metals in the Environment Edited by: Waldron HA. New York: Academy Press Inc; 1980:III-132.

16. Cervantes C, Campos-García J, Devars S, Gutiérrez-Corona F, LozaTavera H, Torres-Guzmán JC, Moreno-Sánchez R: Interactions of chromium with microorganisms and plants. FEMS Microbiol Rev 200I, 25:335-347.

17. Hoch JA: Two-component and phosphorelay signal transduction. Curr Opin Microbiol 2000, 3:165-170.

18. Hoch JA, Silhavy TJ: Two-Component Signal Transduction Washington, DC: American Society for Microbiology Press; 1995.

19. Stock AM, Robinson VL, Goudreau PN: Two-component signal transduction. Annu Rev Biochem 2000, 69:183-215.

20. Thompson JD, Higgins DG, Gibson TJ: CLUSTAL W: improving the sensitivity of progressive multiple sequence alignment through sequence weighting, position-specific gap penalties and weight matrix choice. Nucleic Acids Res 1994, 22:4673-4680.

21. Sanders DA, Gillece-Castro BL, Stock AM, Burlingame AL, Koshland $D E \mathrm{Jr}$ : Identification of the site of phosphorylation of the chemotaxis response regulator protein, CheY. J Biol Chem 1989, 264:21770-21778.

22. Appleby JL, Bourret RB: Proposed signal transduction role for conserved CheY residue Thr87, a member of the response regulator active-site quintet. | Bacteriol 1998, 180:3563-3569.

23. Lukat GS, Lee BH, Mottonen JM, Stock AM, Stock JB: Roles of the highly conserved aspartate and lysine residues in the response regulator of bacterial chemotaxis. J Biol Chem I991, 266:8348-8354.

24. Zhu X, Rebello J, Matsumura P, Volz K: Crystal structures of CheY mutants YI06W and T87I/YI06W. CheY activation correlates with movement of residue 106. J Biol Chem 1997, 272:5000-5006.
25. Brennan RG: The winged-helix DNA-binding motif: another helix-turn-helix takeoff. Cell 1993, 74:773-776.

26. Kenny LJ: Structure/function relationships in OmpR and other winged-helix transcription factors. Curr Opin Microbiol 2002, 5:|35-|4|.

27. Martínez-Hackert E, Stock AM: Structural relationships in the OmpR family of winged-helix transcription factors. J Mol Biol 1997, 269:301-312

28. Wan XF, Xu D: Intrinsic terminator prediction and its application in Synechococcus sp. WH8I02. J Comp Sci Tech 2005, 20:465-482

29. Mitchell JE, Zheng D, Busby SJW, Minchin SD: Identification and analysis of 'extended-10' promoters in Escherichia coli. Nucleic Acids Res 2003, 31 : 4689-4695.

30. Andrews SC, Robinson AK, Rodriguez-Quinones F: Bacterial iron homeostasis. FEMS Microbiol Rev 2003, 27:215-237.

31. Wan XF, VerBerkmoes NC, McCue LA, Stanek D, Connelly H, Hauser LI, Wu L, Liu X, Yan T, Leaphart A, Hettich RL, Zhou J, Thompson DK: Transcriptomic and proteomic characterization of the Fur modulon in the metal-reducing bacterium Shewanella oneidensis. J Bacteriol 2004, I 86:8385-8400.

32. Denef VJ, Klappenbach JA, Patrauchan MA, Florizone C, Rodrigues JLM, Tsoi TV, Verstraete W, Eltis LD, Tiedje JM: Genetic and genomic insights into the role of benzoate-catabolic pathway redundancy in Burkholderia xenovorans LB400. Appl Environ Microbiol 2006, 72:585-595.

33. Marx CJ, Lidstrom ME: Broad-host-range cre-lox system for antibiotic marker recycling in gram-negative bacteria. BioTechniques 2002, 33:1062-1067.

34. Park $\mathrm{CH}$, Keyhan M, Wielinga B, Fendorf S, Matin A: Purification to homogeneity and characterization of a novel Pseudomonas putida chromate reductase. Appl Environ Microbiol 2000, 66:1788-1795.

35. Ruiz N, Silhavy TJ: Sensing external stress: watchdogs of the Escherichia coli cell envelope. Curr Opin Microbiol 2005, 8: $122-126$.

36. Brown SD, Martin M, Deshpande S, Seal S, Huang K, Alm E, Yang $Y$ Wu L, Yan T, Liu X, Arkin A, Chourey K, Zhou J, Thompson DK: Cellular response of Shewanella oneidensis to strontium stress. Appl Environ Microbiol 2006, 72:890-900.

37. Kang HY, Brickman TJ, Beaumont FC, Armstrong SK: Identification and characterization of iron-regulated Bordetella pertussis alcaligin siderophore biosynthesis genes. J Bacteriol 1996, 1 78:4877-4884

38. Ledyard KM, Butler A: Structure of putrebactin, a new dihydroamate siderophore produced by Shewanella putrefaciens. J Biol Inorg Chem 1997, 2:93-97.

39. Andrews SC: Iron storage in bacteria. Adv Microb Physiol 1998 40:28I-35I.

40. Touati D: Iron and oxidative stress in bacteria. Arch Biochem Biophys 2000, 373: $1-6$.

4I. Bereswill S, Waidner U, Odenbreit S, Lichte F, Fassbinder F, Bode G, Kist M: Structural, functional and mutational analysis of the pfr 1998. gene encoding a ferritin from Helicobacter pylori. Microbiology 1998, I44(Pt 9):2505-2516

42. Wai SN Nakayama K, Umene K, Moriya T, Amako K. Construction of a ferritin-deficient mutant of Campylobacter jejuni: contribution of ferritin to iron storage and protection against oxidative stress. Mol Microbiol 1996, 20: I I 27- II 34.

43. Rocha ER, Smith CJ: Transcriptional regulation of the Bacteroides fragilis ferritin gene $(f \operatorname{tn} A)$ by redox stress. Microbiology 2004, I 50 (Pt 7):2125-2। 34.

44. Dorel C, Lejeune P, Rodrigue A: The Cpx system of Escherichia coli, a strategic signaling pathway for confronting adverse conditions and for settling biofilm communities? Res Microbiol 2006, I57:306-314

45. Danese PN, Snyder WB, Cosma CL, Davis LJ, Silhavy T]: The Cpx two-component signal transduction pathway of Escherichia coli regulates transcription of the gene specifying the stressinducible periplasmic protease. Genes Dev 1995, 9:387-398.

46. Raivio TL, Silhavy TJ: Periplasmic stress and ECF sigma factors. Annu Rev Microbiol 200I, 55:59I-624.

47. Batchelor E, Walthers D, Kenney LJ, Goulian M: The Escherichia coli CpxA-CpxR envelope stress response system regulates expression of the porins OmpF and OmpC. J Bacteriol 2005, | 87:5723-573।. 
48. De Wulf $\mathrm{P}$, Kwon O, Lin ECC: The CpxRA signal transduction system of Escherichia coli: growth-related autoactivation and control of unanticipated target operons. J Bacteriol 1999, | 8 I:6772-6778.

49. Danese PN, Silhavy TJ: CpxP, a stress-combative member of the Cpx regulon. J Bacteriol 1998, 180:83I-839.

50. Putman M, van Veen HW, Konings WN: Molecular properties of bacterial multidrug transporters. Microbiol Mol Biol Rev 2000, 64:672-693.

5I. Brickman TJ, Armstrong SK: Bordetella AlcS transporter functions in alcaligin siderophore export and is central to inducer sensing in positive regulation of alcaligin system gene expression. J Bacteriol 2005, 187:3650-366I.

52. Guedon E, Moore CM, Que Q, Wang T, Ye RW, Helmann JD: The global transcriptional response of Bacillus subtilis to manganese involves the MntR, Fur, TnrA and $\sigma^{B}$ regulons. Mol Microbiol 2003, 49: |477-| $49 \mid$.

53. Venkateswaran K, Moser DP, Dollhopf ME, Lies DP, Saffarini DA MacGregor BJ, Ringelberg DB, White DC, Nishijima M, Sano H, Burghardt J, Stackerbrandt E, Nealson KH: Polyphasic taxonomy of the genus Shewanella and description of Shewanella oneidensis sp. nov. Int J Syst Bacteriol 1999, 49:705-724.

54. Schwyn B, Neilands JB: Universal chemical assay for the detection and determination of siderophores. Anal Biochem 1987, 160:47-56.

55. Gao H, Yang ZK, Wu L, Thompson DK, Zhou J: Global transcriptome analysis of the cold shock response of Shewanella oneidensis MR-I and mutational analysis of its classical cold shock proteins. J Bacteriol 2006, 188:4560-4569.

56. Kovach ME, Elzer PH, Hill DS, Robertson GT, Farris MA, Roop RM II, Peterson KM: Four new derivatives of the broad-host-range cloning vector pBBRIMCS, carrying different antibioticresistance cassettes. Gene 1995, 166:175-176.

57. Gao H, Wang Y, Liu X, Yan T, Wu L, Alm E, Arkin A, Thompson DK Zhou J: Global transcriptome analysis of the heat shock response of Shewanella oneidensis. J Bacteriol 2004, I 86:7796-7803.

58. Seo J, Gordish-Dressman H, Hoffman EP: An interactive power analysis tool for microarray hypothesis testing and generation. Bioinformatics 2006, 22:808-814.

59. Gene Expression Omnibus [http://www.ncbi.nlm.nih.gov/geo/]

Publish with Biomed Central and every scientist can read your work free of charge

"BioMed Central will be the most significant development for disseminating the results of biomedical research in our lifetime. "

Sir Paul Nurse, Cancer Research UK

Your research papers will be:

- available free of charge to the entire biomedical community

- peer reviewed and published immediately upon acceptance

- cited in PubMed and archived on PubMed Central

- yours - you keep the copyright

Submit your manuscript here:

http://www.biomedcentral.com/info/publishing_adv.asp
BioMedcentral 